ARTICLE

\title{
Engineering single-atomic ruthenium catalytic sites on defective nickel-iron layered double hydroxide for overall water splitting
}

Panlong Zhai ${ }^{1,6}$, Mingyue Xia ${ }^{2,6}$, Yunzhen Wu¹,6, Guanghui Zhang (10 ${ }^{1}$, Junfeng Gao ${ }^{2}$, Bo Zhang ${ }^{1}$, Shuyan Cao', Yanting Zhang ${ }^{1}$, Zhuwei Li ${ }^{1}$, Zhaozhong Fan ${ }^{1}$, Chen Wang ${ }^{1}$, Xiaomeng Zhang ${ }^{1}$, Jeffrey T. Miller ${ }^{3}$, Licheng Sun (1) ${ }^{1,4,5} \&$ Jungang Hou (i) ${ }^{1 \times}$

Rational design of single atom catalyst is critical for efficient sustainable energy conversion. However, the atomic-level control of active sites is essential for electrocatalytic materials in alkaline electrolyte. Moreover, well-defined surface structures lead to in-depth understanding of catalytic mechanisms. Herein, we report a single-atomic-site ruthenium stabilized on defective nickel-iron layered double hydroxide nanosheets $\left(\mathrm{Ru}_{1} / \mathrm{D}-\mathrm{NiFe} \mathrm{LDH}\right)$. Under precise regulation of local coordination environments of catalytically active sites and the existence of the defects, $\mathrm{Ru}_{1} / \mathrm{D}-\mathrm{NiFe} \mathrm{LDH}$ delivers an ultralow overpotential of $18 \mathrm{mV}$ at $10 \mathrm{~mA} \mathrm{~cm}{ }^{-2}$ for hydrogen evolution reaction, surpassing the commercial Pt/C catalyst. Density functional theory calculations reveal that $\mathrm{Ru}_{1} / \mathrm{D}-\mathrm{NiFe} \mathrm{LDH}$ optimizes the adsorption energies of intermediates for hydrogen evolution reaction and promotes the $\mathrm{O}-\mathrm{O}$ coupling at a $\mathrm{Ru}-\mathrm{O}$ active site for oxygen evolution reaction. The $\mathrm{Ru}_{1} / \mathrm{D}-\mathrm{NiFe} \mathrm{LDH}$ as an ideal model reveals superior water splitting performance with potential for the development of promising water-alkali electrocatalysts.

\footnotetext{
${ }^{1}$ State Key Laboratory of Fine Chemicals, School of Chemical Engineering, Dalian University of Technology, Dalian, China. ${ }^{2}$ Laboratory of Materials Modification by Laser Ion and Electron Beams (Dalian University of Technology), Ministry of Education, Dalian, China. ${ }^{3}$ Davidson School of Chemical Engineering, Purdue University, West Lafayette, IN, USA. ${ }^{4}$ Center of Artificial Photosynthesis for Solar Fuels, School of Science, Westlake University, Hangzhou, China. ${ }^{5}$ Department of Chemistry, School of Engineering Sciences in Chemistry, Biotechnology and Health, KTH Royal Institute of Technology, Stockholm, Sweden. ${ }^{6}$ These authors contributed equally: Panlong Zhai, Mingyue Xia, Yunzhen Wu. ${ }^{凶}$ email: jhou@dlut.edu.cn
} 
$\mathrm{H}$ ydrogen as a sustainable energy is an alternative to traditional fossil fuels to mitigate environmental problems from greenhouse gases ${ }^{1,2}$. Electrochemical water-splitting has been developed as an effective way to generate hydrogen fuel by use of electrocatalysts. At present, Pt- and Ir/Ru-oxide-based catalysts are the benchmark materials for hydrogen evolution reaction (HER) and oxygen evolution reaction (OER) ${ }^{3-6}$. However, their high cost and poor stability limit large-scale utilization. Thus, it is crucial to fabricate highly efficient catalysts for electrocatalytic applications.

Among various materials, $3 d$ transition-metal-based layered double hydroxides (LDHs) containing different metals (e.g., Co, $\mathrm{Ni}, \mathrm{Fe}$, etc.) are promising electrocatalysts due to the unique lamellar structure and abundant active sites ${ }^{7-9}$. For example, LDHs based on $\mathrm{Fe}, \mathrm{Co}, \mathrm{Ni}, \mathrm{Zn}$, and $\mathrm{Mn}$ have been widely investigated for $\mathrm{OER}^{10-16}$. $\mathrm{NiFe}, \mathrm{NiV}$, and $\mathrm{CoFe} \mathrm{LDH}$ s give superior OER activities in our group ${ }^{17-19}$. To optimize the catalytic activity of LDHs, different strategies have been developed through the regulation of morphology, defect formation, charge transfer, etc., ${ }^{20-23}$. With regard to defect engineering, it is an effective approach to modulate catalytic performance. For instance, oxygen vacancies in $\mathrm{Co}_{3} \mathrm{O}_{4}$, sulfur vacancies in $\mathrm{MoS}_{2}$ and $\mathrm{Fe}$ vacancies in $\delta$-FeOOH have been produced ${ }^{24-28}$, optimizing the electrocatalytic activity. However, it is still a challenge to control the structure of active sites in LDHs by defect engineering and develop a correlation between the defects and electrocatalytic performance.
Single atom catalysts (SACs) have emerged as a promising frontier to optimize the catalytic performance, sparking widespread interest by virtue of the appropriate coordination environment, intimate interactions of single atoms with proper supports, and quantum size effects ${ }^{5,6,29-32}$. Often, it is difficult to produce SACs due to facile aggregation of individual metal atoms. Interestingly, two-dimensional (2D) $\mathrm{LDHs}$ provide a favorable platform for the stabilization of SACs due to $2 \mathrm{D}$ flat facet, ultrathin thickness and high surface area ${ }^{29,30}$. In this regard, single atoms anchored 2D LDHs is an ideal model to maximize the OER activity, while simultaneously decreasing the content of single atoms on the support. These sites also offer a useful platform for in-depth understanding of the catalytic mechanism at an atomic level ${ }^{29-32}$. However, HER performance of various LDHs catalysts is rather poor owing to the large energy barrier and sluggish water dissociation kinetics in alkaline media ${ }^{30-32}$. Specifically, it is a challenge to stabilize single atoms on LDHs for water oxidation and reduction in the same alkaline electrolyte. Although various strategies, such as pyrolysis, wet chemistry, atomic layer deposition, etc., have been extensively explored to produce SACs with tailored requirements ${ }^{33-35}$, there is still no simple large-scale synthesis protocol to produce single atoms stabilized on the supports. There is a promising approach to boost the catalytic activity by the introduction of defects into the support, stabilizing single atoms due to the intimate interaction of the resulting structure ${ }^{36-38}$. Combining defect engineering and single atoms supported $2 \mathrm{D} \mathrm{LDHs}$, it is possible to rationally
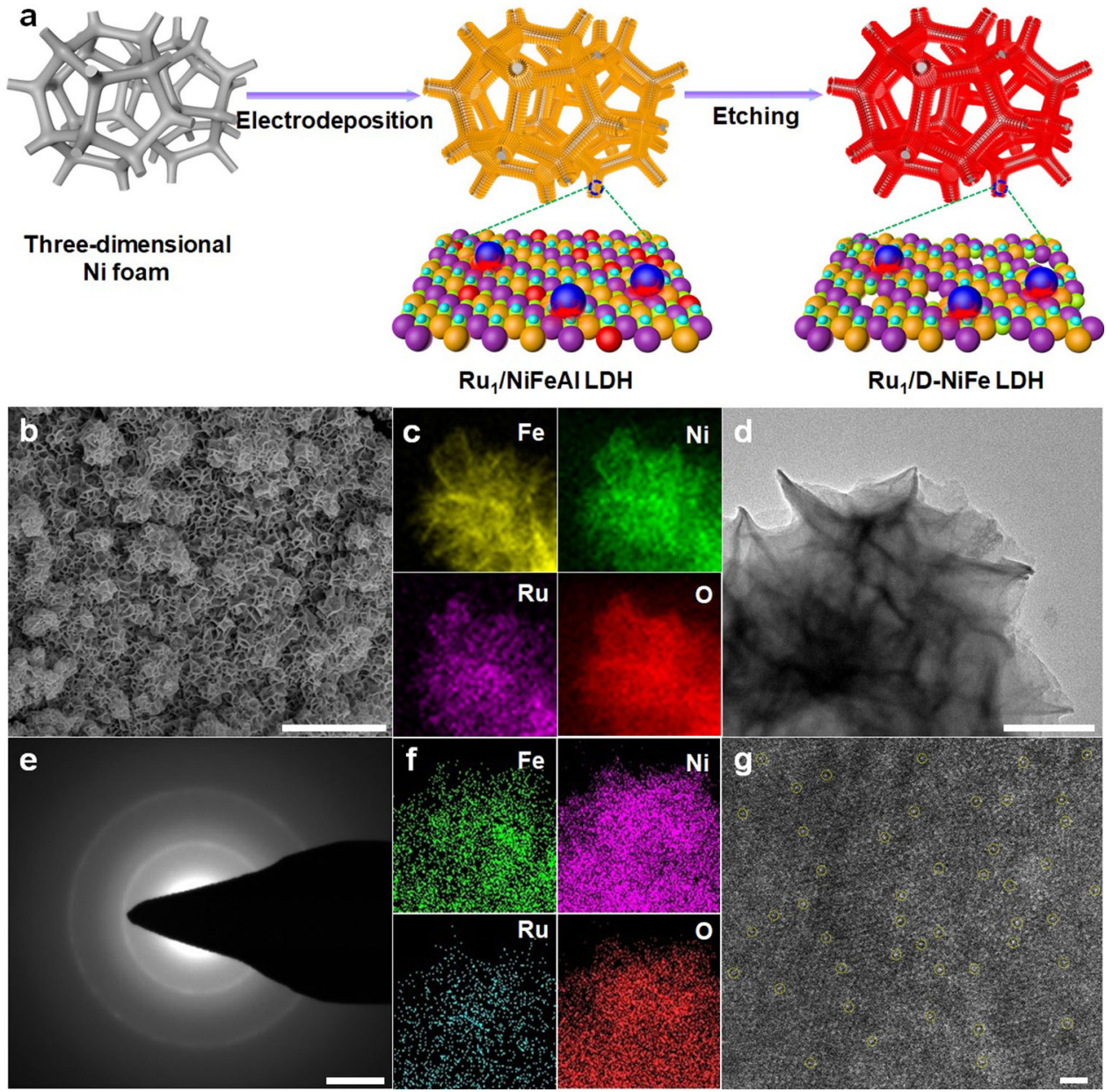

Fig. 1 Schematic representation of synthesis and morphological characterizations. a Synthesis illustration and $\mathbf{b} S E M$ image, $\mathbf{d}$ TEM image, e SAED pattern, and $\mathbf{g}$ aberration-corrected TEM image of $\mathrm{Ru}_{1} / \mathrm{D}-\mathrm{NiFe} \mathrm{LDH}$ (isolated Ru atoms are marked with yellow circles), (cf) elemental mapping of

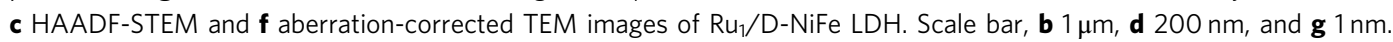


design the atomically dispersed, active single atoms stabilized on defective LDH supports for extraordinary overall water splitting performance in alkaline electrolyte.

In this work, a single-atomic-site ruthenium catalyst stabilized on defective NiFe-LDH is synthesized by a simple electrodeposition and subsequent etching procedure as the straightforward and practical approach. The combined analysis of spherical aberration-corrected transmission electron microscope and X-ray absorption fine structure (XAFS) spectroscopy reveals the existence of $\mathrm{Ru}$ single atoms and in-depth local atomic structures of $\mathrm{Ni}, \mathrm{Fe}$, and $\mathrm{Ru}$ sites. Although $\mathrm{Ru}$ and $\mathrm{NiFe}-\mathrm{LDH}$ have been regarded to be active OER catalysts ${ }^{29,30}$, as-synthesized $\mathrm{Ru}_{1} / \mathrm{D}$ $\mathrm{NiFe} \mathrm{LDH}$ achieves a current density of $10 \mathrm{~mA} \mathrm{~cm}^{-2}$ at an ultralow overpotential of $18 \mathrm{mV}$ and a high turnover frequency of $7.66 \mathrm{~s}^{-1}$ at an overpotential of $100 \mathrm{mV}$ (45 times higher than that of commercial $\mathrm{Pt} / \mathrm{C}$ catalyst) for HER. Inspired by the superior HER and OER performances, the assembled two-electrode cell by $\mathrm{Ru}_{1} / \mathrm{D}-\mathrm{NiFe} \mathrm{LDH}$ reaches an industrial current density of 500 $\mathrm{mA} \mathrm{cm}{ }^{-2}$ at a low cell voltage of $1.72 \mathrm{~V}$ for overall water splitting in alkaline media. Density functional theory (DFT) calculations suggest that $\mathrm{Ru}_{1} / \mathrm{D}-\mathrm{NiFe} \mathrm{LDH}$ optimizes the favorable regulation of $\mathrm{H}$ adsorption energies for $\mathrm{HER}$, and promotes the $\mathrm{O}-\mathrm{O}$ coupling due to the existence of $\mathrm{Ru}-\mathrm{O}$ moieties. Moreover, the abundant number of active sites accelerate the water splitting kinetics, thus enhancing the intrinsic HER and OER activities. This work also establishes a promising platform for future fundamental studies into the role of isolated $\mathrm{Ru}$ single atoms on defective $\mathrm{NiFe} \mathrm{LDH}$ nanosheets in promoting electrocatalytic performance.

\section{Results}

Synthesis and characterization. A single-atomic-site ruthenium catalyst stabilized on defective $\mathrm{NiFe} \mathrm{LDH}$ (denoted as $\mathrm{Ru}_{1} / \mathrm{D}$ $\mathrm{NiFe} \mathrm{LDH}$ ) supported on three-dimensional (3D) skeleton of nickel foam was synthesized by a facile electrodeposition and subsequent etching approach as depicted schematically in Fig. 1a. Notably, the synthetic approach was completed at room temperature and atmospheric pressure without harsh operations. $\mathrm{Ru}$ single atoms stabilized on $\mathrm{NiFeAl} \mathrm{LDH}$ nanosheets $\left(\mathrm{Ru}_{1} / \mathrm{NiFeAl}\right.$ $\mathrm{LDH}$ ) were deposited onto the $3 \mathrm{D}$ conductive substrate by a simple electrodeposition procedure. Then, as-synthesized $\mathrm{Ru}_{1} /$ $\mathrm{NiFeAl} \mathrm{LDH}$ nanosheets were etched in alkali media, removing $\mathrm{Al}$ from $\mathrm{Ru}_{1} / \mathrm{NiFeAl}$ precursor and thus resulting into the formation of $\mathrm{Ru}$ single atoms integrated with defective $\mathrm{NiFe} \mathrm{LDH}$ nanosheets by the precise regulation of the etching time and the content of Ru single atoms.

To shed light on the crystalline structure, X-ray diffraction (XRD) patterns verify that only a set of interplanar angles located at $44.5^{\circ}, 51.8^{\circ}$, and $76.4^{\circ}$ (Supplementary Fig. 1), assigned to (111), (200), and (220) planes of metallic nickel (JCPDS 04-0850), respectively, indicating the amorphous nature of $\mathrm{NiFe} \mathrm{LDH}$ and $\mathrm{Ru}_{1} / \mathrm{D}-\mathrm{NiFe} \mathrm{LDH}$ nanosheets.

To identify the form of $\mathrm{Ru}$ single atoms dispersed on $\mathrm{D}-\mathrm{NiFe}$ LDH supports, field-emission scanning electron microscopy (FESEM), transmission electron microscopy (TEM), high-angle annular dark-field scanning transmission electron microscopy (HAADF-STEM) and spherical aberration-corrected atomic resolution HAADF-STEM were used. As shown in Fig. 1b, SEM image of $\mathrm{Ru}_{1} / \mathrm{D}-\mathrm{NiFe} \mathrm{LDH}$ shows uniform interconnected nanosheets with a smooth surface vertically grown on 3D foam. For comparison, $\mathrm{NiFe} \mathrm{LDH}$ and $\mathrm{Ru}_{1} / \mathrm{NiFeAl} \mathrm{LDH}$ nanosheets were synthesized by electrodeposition, while Ru-doped NiFe LDH (denoted as $\mathrm{NiFeRu} \mathrm{LDH}$ ) nanosheets were prepared by hydrothermal synthesis (Supplementary Fig. 2). Based on the electrodeposition and subsequent etching treatment for various times, the typical morphological nanostructures of $\mathrm{Ru}_{1} / \mathrm{D}-\mathrm{NiFe}$ $\mathrm{LDH}$ are $2 \mathrm{D}$ nanosheets after $24 \mathrm{~h}$ etching treatment (Supplementary Fig. 3). TEM image in Fig. 1d confirms 2D nanosheets structure of $\mathrm{Ru}_{1} / \mathrm{D}-\mathrm{NiFe} \mathrm{LDH}$. The selected-area electron diffraction (SAED) pattern of $\mathrm{Ru}_{1} / \mathrm{D}-\mathrm{NiFe} \mathrm{LDH}$ is presented in Fig. 1e, indicating the amorphous nature with the halo-like diffraction pattern consistent with XRD. From spherical aberration corrected HAADF-STEM image, isolated Ru single atoms as bright spots are homogeneously distributed on the surface of $\mathrm{Ru}_{1} /$ $\mathrm{D}-\mathrm{NiFe} \mathrm{LDH}$ nanosheets without any apparent nanoparticles or clusters, demonstrating the successful synthesis of single-atom electrocatalyst. The elemental mappings of $\mathrm{Ru}_{1} / \mathrm{D}-\mathrm{NiFe} \mathrm{LDH}$ are determined by HAADF-STEM and spherical aberration corrected TEM images (Fig. 1c, f), revealing the existence of $\mathrm{Ni}, \mathrm{Fe}, \mathrm{Ru}$, and $\mathrm{O}$ elements and the homogeneous distribution of Ru single atoms on 2D nanosheets. SEM and TEM images, element mapping and energy-dispersive X-ray (EDX) analysis of different arrays were also conducted (Supplementary Figs. 3-10). The Ru content (1.2 wt\%) of $\mathrm{Ru}_{1} / \mathrm{D}-\mathrm{NiFe} \mathrm{LDH}$ is determined by inductively coupled plasma optical emission spectrometry (ICP-OES) analysis. The atomic force microscopy (AFM) was performed to characterize the average thickness about $4.2 \mathrm{~nm}$ for the nanosheets (Supplementary Fig. 11). These results demonstrate that Ru single atoms stabilized on defective $\mathrm{NiFe} \mathrm{LDH}$ nanosheets have been synthesized by the facile electrodeposition and subsequent etching procedure.

To unravel the chemical composition and electronic properties of the electrocatalysts, X-ray photoelectron spectroscopy (XPS) was conducted (Supplementary Fig. 12). For $\mathrm{Ru}_{1} / \mathrm{D}-\mathrm{NiFe} \mathrm{LDH}$, the peaks located at 856.2 and $874.0 \mathrm{eV}$ with two shakeup satellites are assigned to $\mathrm{Ni} 2 p_{3 / 2}$ and $\mathrm{Ni} 2 p_{1 / 2}$, indicating the $\mathrm{Ni}^{2+}$ oxidation state in $\mathrm{Ru}_{1} / \mathrm{D}-\mathrm{NiFe} \mathrm{LDH}^{11,23}$. The core-level Fe $2 p$ XPS spectrum of $\mathrm{Ru}_{1} / \mathrm{D}-\mathrm{NiFe} \mathrm{LDH}$ displays the typical peaks at 712.1 and $725.7 \mathrm{eV}$, which can be indexed to $\mathrm{Fe} 2 p_{3 / 2}$ and $\mathrm{Fe} 2 p_{1 / 2}$ of $\mathrm{Fe}^{3+9,21}$. In comparison of $\mathrm{NiFe} \mathrm{LDH}$, there are the positive shifts of 0.5 and $0.3 \mathrm{eV}$ in $\mathrm{Ni}$ and Fe XPS of $\mathrm{Ru}_{1} / \mathrm{NiFe} \mathrm{LDH}$ and $\mathrm{Ru}_{1} / \mathrm{D}-\mathrm{NiFe} \mathrm{LDH}$, respectively, indicating the electronic coupling of $\mathrm{Ru}$ single atoms and $\mathrm{D}-\mathrm{NiFe} \mathrm{LDH}^{3,13}$. In $\mathrm{Ru} 3 p$ spectra, the peaks of $\mathrm{Ru} 3 p_{3 / 2}$ and $\mathrm{Ru} 3 p_{1 / 2}$ are located at 463.8 and $486.2 \mathrm{eV}$, intermediate between $\mathrm{Ru}(0)$ and $\mathrm{Ru}(\mathrm{IV})^{39}$. O $1 s$ XPS core-level spectra can be divided into three spin-orbit peaks. The $\mathrm{O} 1 \mathrm{~s}$ signals located at 530.3, 531.6, and $532.4 \mathrm{eV}$ are assigned to metal-oxygen bond (M-O), vacancy with low oxygen coordination and adsorbed hydroxy or $\mathrm{H}_{2} \mathrm{O}$, respectively ${ }^{39}$. Moreover, a positive shift is observed in $\mathrm{O} 1 s$ XPS of $\mathrm{Ru}_{1} / \mathrm{NiFe} \mathrm{LDH}$ and $\mathrm{Ru}_{1} /$ $\mathrm{D}-\mathrm{NiFe} \mathrm{LDH}$ in comparison of $\mathrm{NiFe} \mathrm{LDH}$ (Supplementary Fig. 12), indicating that $\mathrm{Ru}$ atom coordinates with $\mathrm{O}$ atoms through an intimate interaction between $\mathrm{Ru}$ single atoms and defective NiFe LDH support.

To determine the valance states and local coordination structures of $\mathrm{Ru}_{1} / \mathrm{D}-\mathrm{NiFe} \mathrm{LDH}$ at the atomic level, X-ray absorption near-edge structure (XANES) spectroscopy and extended X-ray absorption fine structure (EXAFS) spectroscopy were performed. The $\mathrm{Ru}$ K-edge XANES spectra of $\mathrm{Ru}_{1} / \mathrm{D}-\mathrm{NiFe}$ $\mathrm{LDH}$ in Fig. 2a shows that the edge energy is between $\mathrm{Ru}$ foil and $\mathrm{RuO}_{2}$, demonstrating a cationic environment. In the Fouriertransform EXAFS (FT-EXAFS) spectra in Fig. 2d, $\mathrm{Ru}_{1} / \mathrm{D}-\mathrm{NiFe}$ $\mathrm{LDH}$ has a first shell Ru-O peak at $1.56 \AA$ (phase uncorrected distance) and a weak $\mathrm{Ru}-\mathrm{O}-\mathrm{M}(\mathrm{M}=\mathrm{Ni}$ or $\mathrm{Fe})$ in the higher shells. Compared to $\mathrm{Ru}$ foil and $\mathrm{RuO}_{2}$, there is no characteristic peak for $\mathrm{Ru}-\mathrm{Ru}$ scattering in $\mathrm{Ru}_{1} / \mathrm{D}-\mathrm{NiFe} \mathrm{LDH}$, which is consistent with the analysis of aberration-corrected TEM image of atomically dispersed $\mathrm{Ru}$ atoms on $2 \mathrm{D} \mathrm{LDH}$ nanosheets ${ }^{29,40}$. The analysis of coordination configuration was conducted by model-based EXAFS fitting. The coordination number of $\mathrm{Ru}-\mathrm{O}$ in first coordination sphere of $\mathrm{Ru}_{1} / \mathrm{D}-\mathrm{NiFe}-\mathrm{LDH}$ is estimated to 

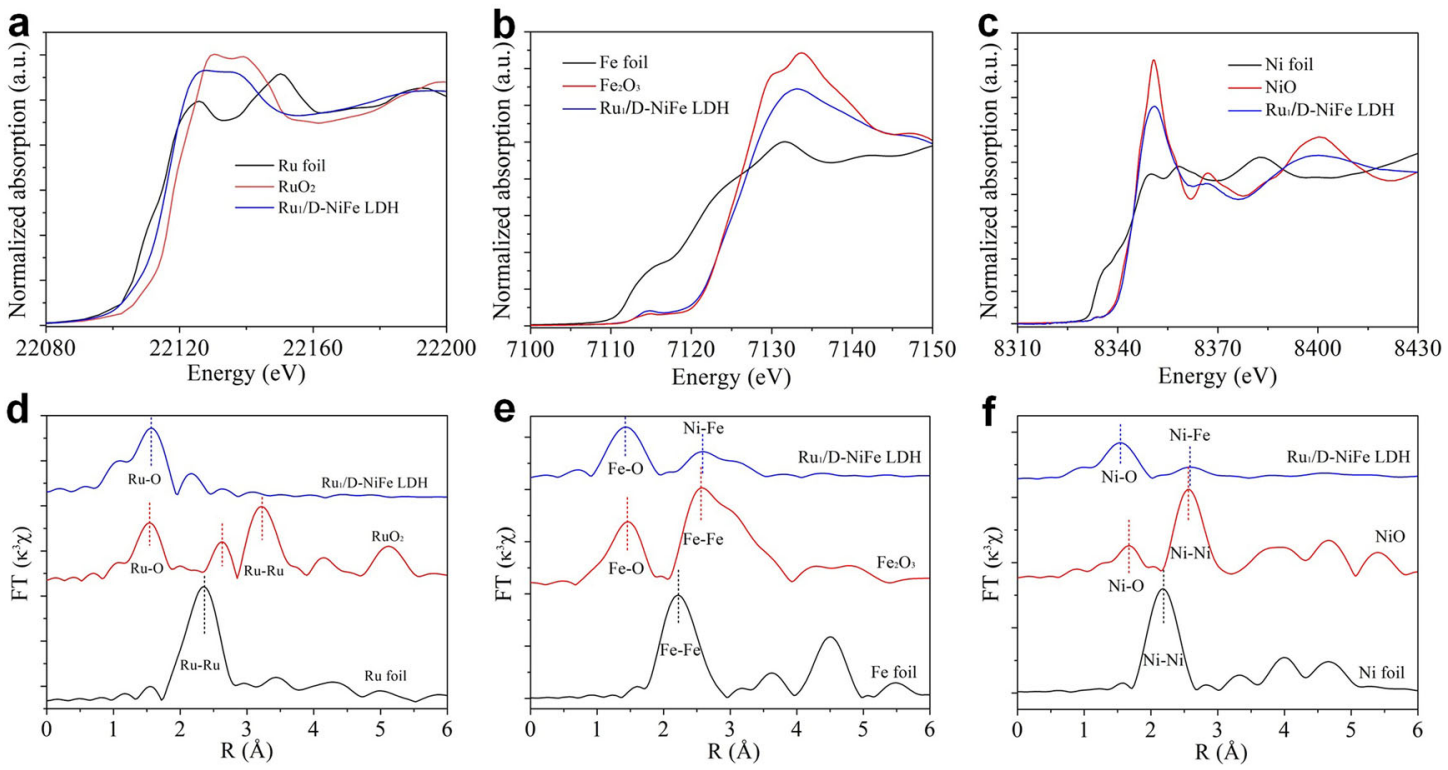

Fig. 2 X-ray absorption spectroscopy characterizations. a XANES spectra at Ru K-edge of Ru $/$ D-NiFe LDH, Ru foil, and RuO . b XANES spectra at Fe K-edge of $\mathrm{Ru}_{1} / \mathrm{D}$-NiFe LDH, Fe foil, and $\mathrm{Fe}_{2} \mathrm{O}_{3}$. c XANES spectra at Ni K-edge of $\mathrm{Ru}_{1} / \mathrm{D}-\mathrm{NiFe} \mathrm{LDH}$, Ni foil, and NiO. d-f Fourier-transform EXAFS spectra from a-c.

be 3.7, implying the existence of coordinatively unsaturated $\mathrm{RuO}_{4}$ sites (Supplementary Table 1 and Supplementary Figs. 13 and 14). XANES simulation on $\mathrm{Ru}_{1} / \mathrm{D}-\mathrm{NiFe}-\mathrm{LDH}$ presents that the white line and post-edge features are well reproduced in experimental and simulated spectra (Supplementary Fig. 15). All above results indicate that atomically dispersed $\mathrm{Ru}$ is successfully immobilized on $\mathrm{D}-\mathrm{NiFe} \mathrm{LDH}$ nanosheets by coordianting with $\mathrm{O}$ atoms. As shown in the Fe K-edge XANES spectra in Fig. 2b, a pre-edge energy of $7114.8 \mathrm{eV}$ for $\mathrm{Ru}_{1} / \mathrm{D}-\mathrm{NiFe} \mathrm{LDH}$, identical to that of $\mathrm{Fe}_{2} \mathrm{O}_{3}$, suggests the presence of $\mathrm{Fe}^{3+}$, which is in agreement with the XPS analysis. A slightly higher pre-edge intensity than that of $\mathrm{Fe}_{2} \mathrm{O}_{3}$ likely indicates a distorted octahedral coordination geometry of the $\mathrm{Fe}^{3+}$ sites in $\mathrm{Ru}_{1} / \mathrm{D}-\mathrm{NiFe} \mathrm{LDH}^{41}$. The R-space shows two prominent coordination peaks at 1.44 and $2.58 \AA$ (phase uncorrected distance), which can be assigned to the $\mathrm{Fe}-\mathrm{O}$ peak and $\mathrm{Fe}-\mathrm{Ni} / \mathrm{Fe}$ peak. Moreover, the average $\mathrm{Fe}-\mathrm{Ni} / \mathrm{Fe}$ distance in $\mathrm{Ru}_{1} / \mathrm{D}-\mathrm{NiFe} \mathrm{LDH}$ is slightly shorter than that of $\mathrm{NiFe} \mathrm{LDH}$, indicating the presence of coordinatively unsaturated sites and structure distortion around $\mathrm{Fe}$ center ${ }^{40,41}$. As for $\mathrm{Ni} \mathrm{K}$ edge, the pre-edge peak of $\mathrm{Ru}_{1} / \mathrm{D}-\mathrm{NiFe} \mathrm{LDH}(8333.4 \mathrm{eV})$ is similar to that of the $\mathrm{NiO}$ reference (Fig. 2), indicating the presense of $\mathrm{Ni}^{2+}$, which is in accordance with the analysis of XPS spectra. The similar change of Ni or Fe EXAFS was obtained with the precense of abundant metal defect sites in $\mathrm{Ru}_{1} / \mathrm{D}-\mathrm{NiFe} \mathrm{LDH}$ nanosheets $26,42,43$. Based on the EXAFS analysis, the abundant number of defects in the LDH nanosheets could play an important role in stabilizing $\mathrm{Ru}$ atoms on $\mathrm{LDH}$ support.

Electrocatalytic performance for HER. Owing to the kinetically sluggish electrocatalytic HER by $\mathrm{NiFe} \mathrm{LDH}$, it is important to optimize the HER activity. The electrocatalytic HER performance of all electrocatalysts by linear sweep voltammetry (LSV) was evaluated using a typical three-electrode system in nitrogensaturated $1 \mathrm{M} \mathrm{KOH}$ electrolyte. As shown in Fig. $3 \mathrm{a}, \mathrm{b}, \mathrm{Ru}_{1} / \mathrm{D}$ $\mathrm{NiFe} \mathrm{LDH}$ with only $1.2 \mathrm{wt} \%$ of Ru single atoms has the catalytically most active polarization curve with a near zero onset potential. $\mathrm{Ru}_{1} / \mathrm{D}-\mathrm{NiFe} \mathrm{LDH}$ delivers the overpotentials of 18 and $61 \mathrm{mV}$ to reach the current densities of 10 and $100 \mathrm{~mA} \mathrm{~cm}^{-2}$, which are lower than the benchmark catalysts, 33 and $90 \mathrm{mV}$ for $\mathrm{Pt} / \mathrm{C}$ catalyst, and 272 and $371 \mathrm{mV}$ for $\mathrm{NiFe} \mathrm{LDH}$, indicating that
$\mathrm{Ru}$ single atoms stabilized on $\mathrm{D}-\mathrm{NiFe} \mathrm{LDH}$ nanosheets can significantly improve the electrocatalytic performance. In comparison to $\mathrm{Ru}_{1} / \mathrm{D}-\mathrm{NiFe} \mathrm{LDH}$, the HER electrocatalytic activities of $\mathrm{Ru}$ single atoms supported on $\mathrm{NiFe} \mathrm{LDH}\left(\mathrm{Ru}_{1} / \mathrm{NiFe} \mathrm{LDH}\right), \mathrm{NiFeAl}$ $\mathrm{LDH}\left(\mathrm{Ru}_{1} / \mathrm{NiFeAl} \mathrm{LDH}\right)$ and defective $\mathrm{NiFe} \mathrm{LDH}(\mathrm{D}-\mathrm{NiFe} \mathrm{LDH})$ are low (Supplementary Fig. 16), highlighting the important role of the defects and $\mathrm{Ru}$ single atoms on NiFe LDH surface. The difference between $\mathrm{Ru}_{1} / \mathrm{D}-\mathrm{NiFe} \mathrm{LDH}$ and $\mathrm{Ru}_{1} / \mathrm{NiFe} \mathrm{LDH}$ suggests that defect-rich $\mathrm{NiFe} \mathrm{LDH}$ has a stronger interaction with $\mathrm{Ru}$ single atoms than $\mathrm{NiFe} \mathrm{LDH}$, leading to a significant enhancement in the HER performance. By tuning the etching time and the amount of $\mathrm{Ru}$ single atoms in $\mathrm{Ru}_{1} / \mathrm{D}-\mathrm{NiFe} \mathrm{LDH}$, the catalytic performance can be optimized (Supplementary Fig. 17). Tafel plots were derived from the polarization curves to capture deeper insight of the electrochemical reaction kinetics (Fig. 3c). The Tafel slope of $\mathrm{Ru}_{1} / \mathrm{D}-\mathrm{NiFe} \mathrm{LDH}$ is as low as $29 \mathrm{mV} \mathrm{dec}^{-1}$, which is lower than those of $\mathrm{Ru}_{1} / \mathrm{NiFe} \mathrm{LDH}\left(36 \mathrm{mV} \mathrm{dec}^{-1}\right)$ and $\mathrm{NiFe} \mathrm{LDH}\left(101 \mathrm{mV} \mathrm{dec}^{-1}\right)$, indicating that the reaction pathways follow the Volmer-Tafel mechanism and the chemical recombination of adsorbed $\mathrm{H}$ is the rate-determining step $^{35}$. Moreover, the exchange current density $\left(j_{0}\right)$ determined by extrapolating the Tafel plot of $\mathrm{Ru}_{1} / \mathrm{D} \mathrm{NiFe} \mathrm{LDH}$ is estimated at $2.6 \mathrm{~mA} \mathrm{~cm}^{-2}$ (Supplementary Fig. 18), which is better than those of other catalysts, revealing the excellent inherent electrocatalytic activity. With regard to low overpotential and Tafel slope, the apparent merits of $\mathrm{Ru}_{1} / \mathrm{D}-\mathrm{NiFe} \mathrm{LDH}$ are significantly better than those reported for commercial $\mathrm{Pt} / \mathrm{C}$ and most HER catalysts (Fig. 3d and Supplementary Table 2). Interestingly, an impressive mass activity, $14,650 \mathrm{~A} \mathrm{~g}_{\text {metal }}{ }^{-1}$ of $\mathrm{Ru}_{1} / \mathrm{D}-\mathrm{NiFe} \mathrm{LDH}$ was achieved at the overpotential of $100 \mathrm{mV}$, which is $\sim 7$ times higher than that of $\mathrm{Ru}_{1} / \mathrm{NiFe} \mathrm{LDH}\left(2420 \mathrm{~A} \mathrm{~g}_{\text {metal }^{-1}}{ }^{-1}\right.$ ), and $\sim 45$ times higher than that of the $\mathrm{Pt} / \mathrm{C}$ catalyst $\left(320 \mathrm{~A} \mathrm{~g}_{\text {metal }^{-1}}{ }^{-1}\right.$ ). The turnover frequency (TOF) was calculated (Fig. 3e), assuming all Ru are presented as active sites to quantify the catalytic efficiency. The TOF of $\mathrm{Ru}_{1} / \mathrm{D}$ $\mathrm{NiFe} \mathrm{LDH}$ is $7.66 \mathrm{~s}^{-1}$ at the overpotential of $100 \mathrm{mV}$, which is $\sim 6$ times higher than that of $\mathrm{Ru}_{1} / \mathrm{NiFe} \mathrm{LDH}\left(1.27 \mathrm{~s}^{-1}\right)$, and $\sim 24$ times higher than that of $\mathrm{Pt} / \mathrm{C}$ catalyst $\left(0.32 \mathrm{~s}^{-1}\right)$ as well as higher than those of most reported catalysts (Supplementary Table 3), implying the highly efficient utilization of $\mathrm{Ru}$ single atoms on defective LDH support. To evaluate the active surface area of the 

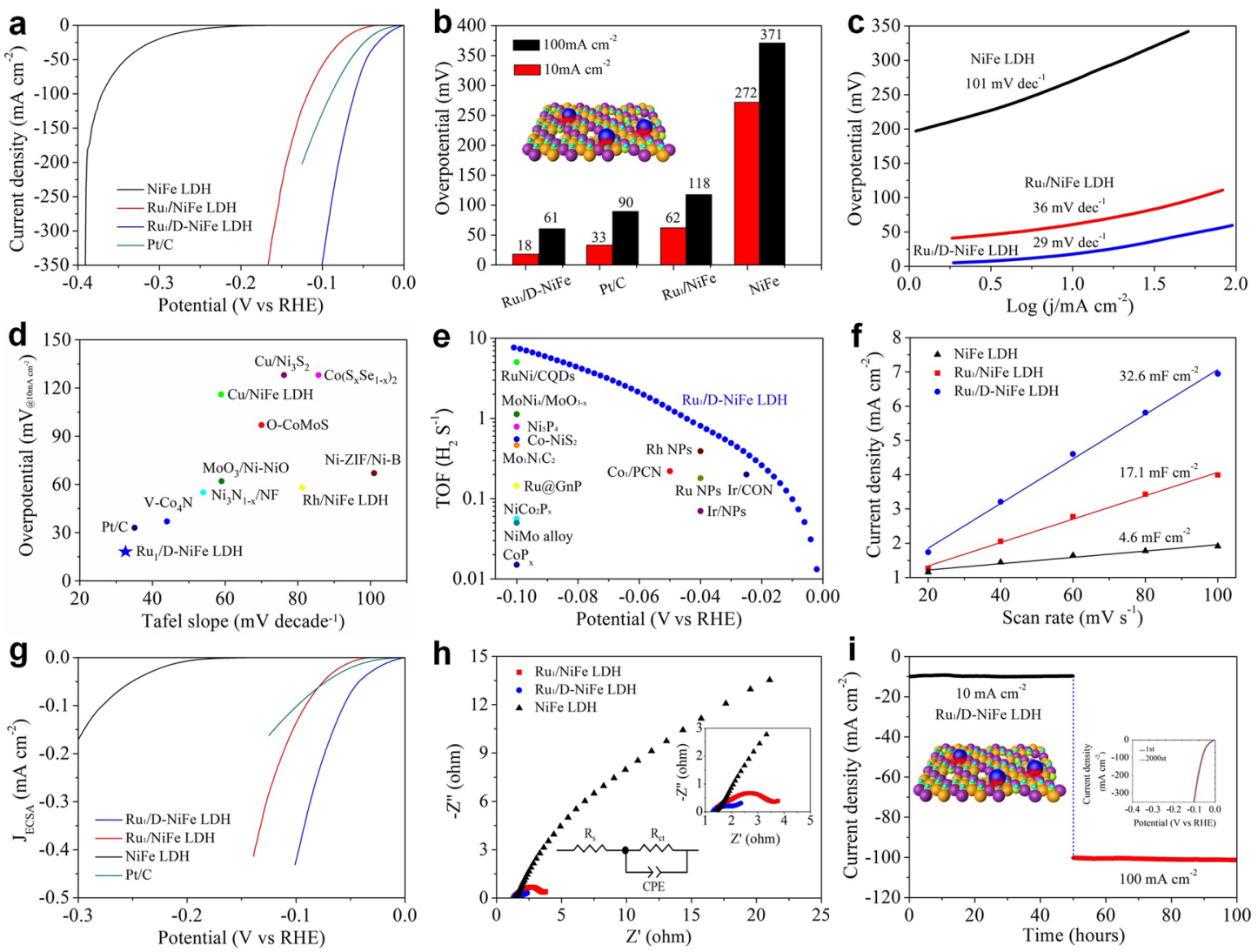

Fig. 3 HER catalytic performance. a HER polarization curves, b overpotentials at typical current densities, $\mathbf{c}$ Tafel slopes of various LDHs, d comparison of merit with respect to both kinetics (Tafel slope) and activity (the overpotential at $10 \mathrm{~mA} \mathrm{~cm}{ }^{-2}$ ), e TOF values of Ru $/ \mathrm{D}-\mathrm{NiFe} L D H$ (blue dots), together with reported HER electrocatalysts at typical overpotentials, $\mathbf{f}$ double-layer capacitances $\left(C_{d 1}\right), \mathbf{g}$ polarization curves with the current normalized to ECSA of NiFe $\mathrm{LDH}, \mathrm{Ru}_{1} / \mathrm{NiFe} \mathrm{LDH}$, and $\mathrm{Ru}_{1} / \mathrm{D}-\mathrm{NiFe} \mathrm{LDH}$, $\mathbf{h}$ electrochemical impedance spectroscopy, $\mathbf{i}$ time-dependent current density curves of Ru$/ \mathrm{D}-\mathrm{NiFe} \mathrm{LDH}$ at -0.018 and $-0.061 \mathrm{~V}$ vs. RHE. Inset is LSV curves before and after 2000 cycles.

electrocatalysts, the electrochemical surfaces areas (ECSA) were obtained by double-layer capacitance $\left(C_{\mathrm{dl}}\right)$ in non-Faradaic potential region ${ }^{22-35}$. $\mathrm{Ru}_{1} / \mathrm{D}-\mathrm{NiFe} \mathrm{LDH}$ has the highest $C_{\mathrm{dl}}$ value of $32.6 \mathrm{mF} \mathrm{cm}^{-2}$, which is 1.9 - and 7.1-fold times higher than those of $\mathrm{Ru} / \mathrm{NiFe} \mathrm{LDH}$ and $\mathrm{NiFe} \mathrm{LDH}$, respectively (Fig. $3 \mathrm{f}$ and Supplementary Fig. 19). Especially, the current densities of $\mathrm{NiFe} \mathrm{LDH}, \mathrm{Ru}_{1} / \mathrm{NiFe} \mathrm{LDH}, \mathrm{Ru}_{1} / \mathrm{D}-\mathrm{NiFe} \mathrm{LDH}$, and commercial $\mathrm{Pt} / \mathrm{C}$ were normalized to ECSA (Fig. $3 \mathrm{~g}$ and Supplementary Figs. 20, 21), demonstrating the highest instrinsic activity of $\mathrm{Ru}_{1} /$ $\mathrm{D}-\mathrm{NiFe} \mathrm{LDH}$. Electrochemical impedance spectroscopy (EIS) measurement was performed to get insight into the kinetics of charge transfer. Based on Nyquist plots, the charge transfer resistance $\left(R_{\mathrm{ct}}\right)$ of $\mathrm{Ru}_{1} / \mathrm{D}-\mathrm{NiFe} \mathrm{LDH}$ is smaller than those of other electrocatalysts, demonstrating a facilitated HER charge transfer kinetics and a fast Faradaic reaction process at the interface between the catalyst and the electrolyte (Fig. $3 \mathrm{~h}$ and Supplementary Fig. 22). Thus, the synergistic effect of the defects and $\mathrm{Ru}$ single atoms faciliates the charge transport and increases the number of active sites. To identify the durability of the catalyst, LSV curves before and after 2000 cycles tests show little change (Fig. 3i). The time-dependent current density curves of $\mathrm{Ru}_{1} / \mathrm{D}$ $\mathrm{NiFe} \mathrm{LDH}$ were recorded, delivering 10 and $100 \mathrm{~mA} \mathrm{~cm}^{-2}$ at -0.018 and $-0.061 \mathrm{~V}$ vs. RHE for $100 \mathrm{~h}$. Negligible change of current density is also observed in Fig. 3i, indicating the excellent cycling and long-term stability. The extraordinary stability is ascribed to the unique structures of $\mathrm{Ru}$ single atoms integrated $\mathrm{NiFe} \mathrm{LDH}$ nanosheets with abundant defect sites, stabilizing $\mathrm{Ru}$ single atoms at atomic level and facilitating the charge transfer in $\mathrm{Ru}_{1} / \mathrm{D}-\mathrm{NiFe} \mathrm{LDH}$. Afterwards, hydrogen generation was analyzed
(Supplementary Fig. 23), indicating that Faradaic efficiency (FE) of $\mathrm{Ru}_{1} / \mathrm{D}-\mathrm{NiFe} \mathrm{LDH}$ is close to $100 \%$ for real water splitting.

Electrocatalytic performance for OER. The OER performace of the electrocatalysts was also evaluated in oxygen-saturated $1 \mathrm{M}$ $\mathrm{KOH}$ solution. For $\mathrm{Ru}_{1} / \mathrm{D}-\mathrm{NiFe} \mathrm{LDH}$, a sharp increase in the anodic current response was observed at an onset potential of $1.41 \mathrm{~V}$ vs. RHE. Strikingly, $\mathrm{Ru}_{1} / \mathrm{D}-\mathrm{NiFe} \mathrm{LDH}$ increases dramatically after the onset potential with small overpotentials of 189 and $220 \mathrm{mV}$ at 10 and $100 \mathrm{~mA} \mathrm{~cm}^{-2}$, which is lower than those of $\mathrm{NiFe} \mathrm{LDH}(250$ and $290 \mathrm{mV})$ and commericial $\mathrm{IrO}_{2}(350 \mathrm{mV})$ in Fig. $4 a, b$, demonstrating remarkable OER activity. What is the most significant is that a high current density up to $300 \mathrm{~mA} \mathrm{~cm}^{-2}$ can be achieved at $1.47 \mathrm{~V}$ vs. $\mathrm{RHE}$ for $\mathrm{Ru}_{1} / \mathrm{D}-\mathrm{NiFe} \mathrm{LDH}$ owing to efficient charge transfer, large electrochemical surface area and unique architecture as well as the synergistic effect of $\mathrm{Ru}$ single atoms and the defective support. In comparison of $\mathrm{Ru}_{1} / \mathrm{D}-\mathrm{NiFe}$ $\mathrm{LDH}, \mathrm{Ru}_{1} / \mathrm{NiFe} \mathrm{LDH}, \mathrm{Ru}_{1} / \mathrm{NiFeAl} \mathrm{LDH}$ and $\mathrm{D}-\mathrm{NiFe} \mathrm{LDH}$ present the inferior OER electrocatalytic activities (Supplementary Fig. 24). Compared to Ru-doped $\mathrm{NiFe}(\mathrm{NiFeRu}) \mathrm{LDH}$ by hydrothermal process ${ }^{44,45}, \mathrm{Ru}_{1} / \mathrm{NiFe} \mathrm{LDH}$ shows high OER activity (Supplementary Fig. 25), demonstrating this electrodeposition approach is a promising strategy to fabricate the integtration of single atoms and 2D nanomaterials. The superior $\mathrm{Ru}_{1} / \mathrm{D}-\mathrm{NiFe} \mathrm{LDH}$ is achieved by regluating the etching time and the amount of $\mathrm{Ru}$ single atoms in $\mathrm{Ru}_{1} / \mathrm{D}-\mathrm{NiFe} \mathrm{LDH}$ (Supplementary Fig. 25). With regard to the reproducibility, ten $\mathrm{Ru}_{1} / \mathrm{D}$ $\mathrm{NiFe} \mathrm{LDH}$ electrodes were synthesized by the same approach. There is no big change upon the potentials of $1.419,1.448$ and 

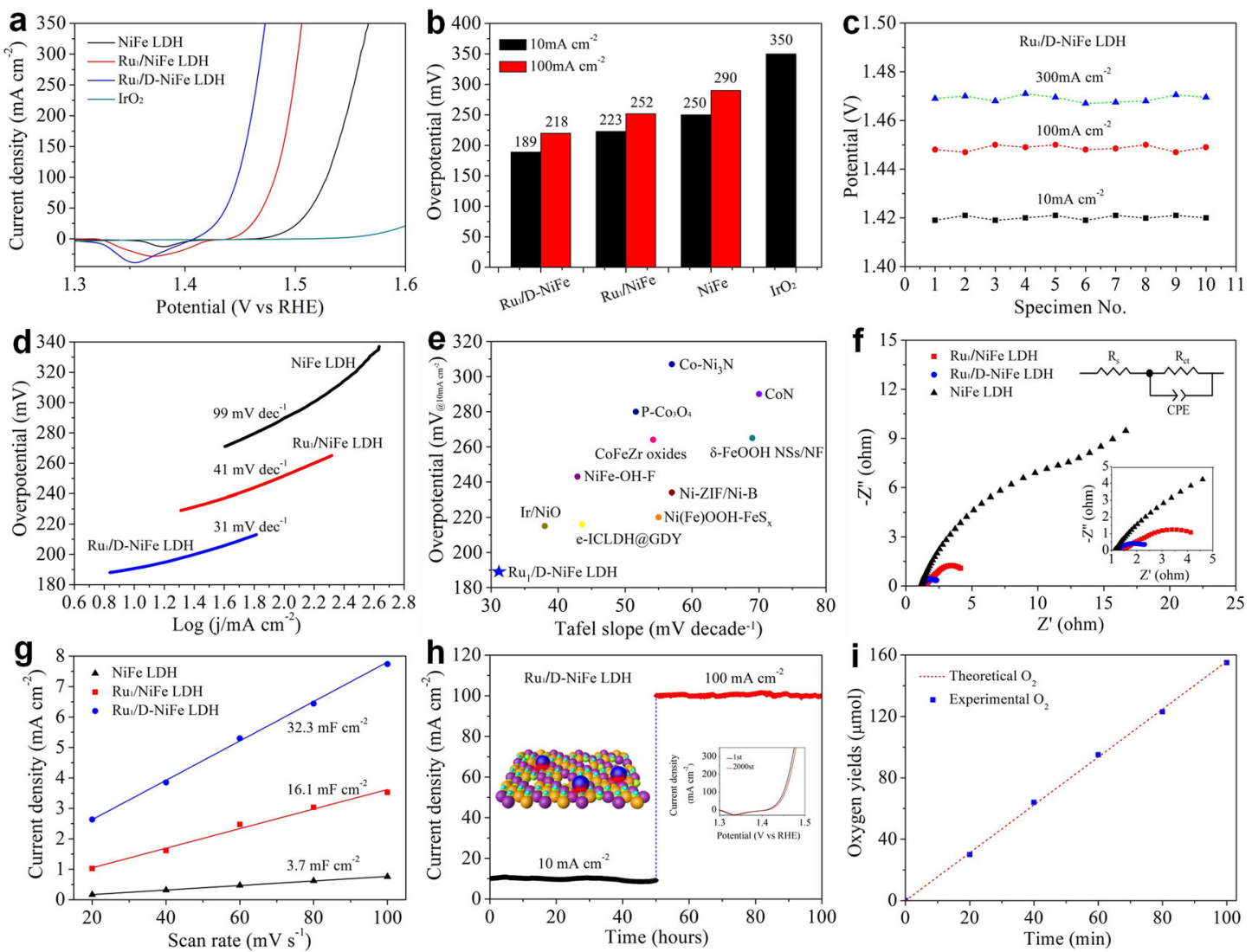

Fig. 4 OER catalytic performance. a OER polarization curves, b overpotentials at typical current densities, $\mathbf{c}$ potentials at current densities of 10, 100, and $300 \mathrm{~mA} \mathrm{~cm}^{-2}$ for ten $\mathrm{Ru}_{1} / \mathrm{D}$-NiFe LDH electrodes, $\mathbf{d}$ Tafel slopes of various LDHs, e comparison of merit with respect to both kinetics (Tafel slope) and activity (the overpotential at $10 \mathrm{~mA} \mathrm{~cm}^{-2}$ ), f electrochemical impedance spectroscopy, $\mathbf{g}$ double-layer capacitances $\left(\mathrm{C}_{\mathrm{dl}}\right)$ of of $\mathrm{NiFe} \mathrm{LDH}, \mathrm{Ru_{1 }} / \mathrm{NiFe} \mathrm{LDH}$, and $\mathrm{Ru}_{1} / \mathrm{D}-\mathrm{NiFe} \mathrm{LDH}, \mathbf{h}$ time-dependent current density curves of $\mathrm{Ru}_{1} / \mathrm{D}-\mathrm{NiFe} \mathrm{LDH}$ at 1.419 and $1.448 \mathrm{~V}$ vs. RHE. Inset is LSV curves before and after 2000 cycles. $\mathbf{i}$ The amount of gas theoretically calculated and experimentally measured vs. time by use of $\mathrm{Ru}_{1} / \mathrm{D}-\mathrm{NiFe} \mathrm{LDH}$.

$1.469 \mathrm{~V}$ vs. RHE to deliver the current densities of 10,100 , and $300 \mathrm{~mA} \mathrm{~cm}^{-2}$, as shown in Fig. $4 \mathrm{c}$, demonstrating the excellent reproducibility. In addition to the low overpotential and high current density, the Tafel plot in Fig. 4 d shows that $\mathrm{Ru}_{1} / \mathrm{D}-\mathrm{NiFe}$ LDH has a small slope of $31 \mathrm{mV} \mathrm{dec}^{-1}$, which is lower than those of $\mathrm{Ru}_{1} / \mathrm{NiFe} \mathrm{LDH}\left(41 \mathrm{mV} \mathrm{dec}^{-1}\right)$ and $\mathrm{NiFe} \mathrm{LDH}\left(99 \mathrm{mV} \mathrm{dec}^{-1}\right)$, respectively, suggesting favorable OER kinetics in alkaline electrolyte. The combined merits of $\mathrm{Ru}_{1} / \mathrm{D}-\mathrm{NiFe} \mathrm{LDH}$ including low overpotentials and Tafel slopes (Fig. 4e), are superior to commercial $\mathrm{IrO}_{2}$ and most reported OER catalysts (Supplementary Table 4) ${ }^{15,46-54}$. Particularly, the mass activity, 11,980 $\mathrm{A} \mathrm{g}_{\text {metal }}{ }^{-1}$ of $\mathrm{Ru}_{1} / \mathrm{D}-\mathrm{NiFe} \mathrm{LDH}$ was obtained at the overpotential of $240 \mathrm{mV}$, suggesting that $\mathrm{Ru}$ single atoms supported on defective $\mathrm{NiFe} \mathrm{LDH}$ nanosheets can dramatically maximize the OER activity.

From Nyquist plots, $\mathrm{Ru}_{1} / \mathrm{D}-\mathrm{NiFe} \mathrm{LDH}$ exhibits a smaller semicircle diameter than others, implying the faster charge transfer between the electrodes and the electrolyte (Fig. 4f). To investigate the origin of the enhancement of OER performance, a large $C_{\mathrm{dl}}$ value, $32.3 \mathrm{mF} \mathrm{cm}^{-2}$ was obtained for $\mathrm{Ru}_{1} / \mathrm{D}-\mathrm{NiFe} \mathrm{LDH}$, which is higher than those of $\mathrm{Ru}_{1} / \mathrm{NiFe} \mathrm{LDH}$ and NiFe LDH (Fig. $4 \mathrm{~g}$ and Supplementary Fig. 26), indicating an abundant number of active sites. $\mathrm{Ru}_{1} / \mathrm{D}-\mathrm{NiFe} \mathrm{LDH}$ also has impressive durability in alkaline media (Fig. 4h). The amount of oxygen was measured in comparison of actual quantity against theoretical quantity at differernt reaction time (Fig. 4i), revealing that the FE of $\mathrm{Ru}_{1} / \mathrm{D}-\mathrm{NiFe} \mathrm{LDH}$ is $99.6 \%$ during OER process and the observed catalytic current originates exclusively from water oxidation. Accordingly, the intimate interaction between $\mathrm{Ru}$ single atoms and defective $\mathrm{NiFe} \mathrm{LDH}$ nanosheets is beneficial to the OER enhancement of $\mathrm{Ru}_{1} / \mathrm{D}-\mathrm{NiFe} \mathrm{LDH}$.

Electrocatalytic performance for overall water splitting. Inspired by the superior hydrogen and oxygen evolution performance of $\mathrm{Ru}_{1} / \mathrm{D}-\mathrm{NiFe} \mathrm{LDH}$, a two-electrode configuration electrolyzer $\left(\mathrm{Ru}_{1} / \mathrm{D}-\mathrm{NiFe} \mathrm{LDH} \| \mathrm{Ru}_{1} / \mathrm{D}-\mathrm{NiFe} \mathrm{LDH}\right)$ for overall water splitting (Fig. 5a) was assembled by $\mathrm{Ru}_{1} / \mathrm{D}-\mathrm{NiFe} \mathrm{LDH}$ as both the anode and cathode. The polarization curves of as-prepared $\mathrm{Ru}_{1} /$ $\mathrm{D}-\mathrm{NiFe} \mathrm{LDH} \| \mathrm{Ru}_{1} / \mathrm{D}-\mathrm{NiFe} \mathrm{LDH}$ and $\mathrm{Pt} / \mathrm{C} \| \mathrm{IrO}_{2}$ as the benchmark catalysts are displayed in Fig. 5 b. $\mathrm{Ru}_{1} / \mathrm{D}-\mathrm{NiFe} \mathrm{LDH}$ only requires the low cell voltages of 1.44 and $1.54 \mathrm{~V}$ to reach current densities of 10 and $100 \mathrm{~mA} \mathrm{~cm}^{-2}$, respectively, which is even better than $\mathrm{Pt} / \mathrm{C} \| \mathrm{IrO}_{2}$ and most reported bifunctional electrocatalysts (Fig. $5 \mathrm{~d}$ and Supplementary Table 5). Particularly, $\mathrm{Ru}_{1} /$ $\mathrm{D}-\mathrm{NiFe} \mathrm{LDH}$ as a quintessence drives the typical two-electrode cell to the industrially required current density as high as $500 \mathrm{~mA}$ $\mathrm{cm}^{-2}$ at an ultralow cell voltage of $1.72 \mathrm{~V}$. The overpotential at $500 \mathrm{~mA} \mathrm{~cm}^{-2}$ by $\mathrm{Ru}_{1} / \mathrm{D}-\mathrm{NiFe} \mathrm{LDH}$ is lower than most of reported bifunctional catalysts $\left(175 \mathrm{~mA} \mathrm{~cm}^{-2}\right.$ at $1.8 \mathrm{~V}$ for NiVIr$\mathrm{LDH}|| \mathrm{NiVRu}-\mathrm{LDH}^{42}, \quad 500 \mathrm{~mA} \mathrm{~cm}^{-2}$ at $1.735 \mathrm{~V}$ for NiMoN\| NiMoN@NiFeN ${ }^{55}, 190 \mathrm{~mA} \mathrm{~cm}^{-2}$ at $1.7 \mathrm{~V}$ for Rh/NiFeRh-LDH $\mathrm{Rh} / \mathrm{NiFeRh}-\mathrm{LDH}^{56}, 50 \mathrm{~mA} \mathrm{~cm}{ }^{-2}$ at $1.76 \mathrm{~V}$ for $\mathrm{P}_{-} \mathrm{Co}_{3} \mathrm{O}_{4} \| \mathrm{P}-$ $\mathrm{Co}_{3} \mathrm{O}_{4}{ }^{24}$, etc.), indicating promising potential for industrial overall water splitting application.

Significantly, as-assembled $\mathrm{Ru}_{1} / \mathrm{D}-\mathrm{NiFe} \quad \mathrm{LDH} \| \mathrm{Ru}_{1} / \mathrm{D}-\mathrm{NiFe}$ $\mathrm{LDH}$ electrodes presented long-term stability by timedependent current density curves. There is no obvious 

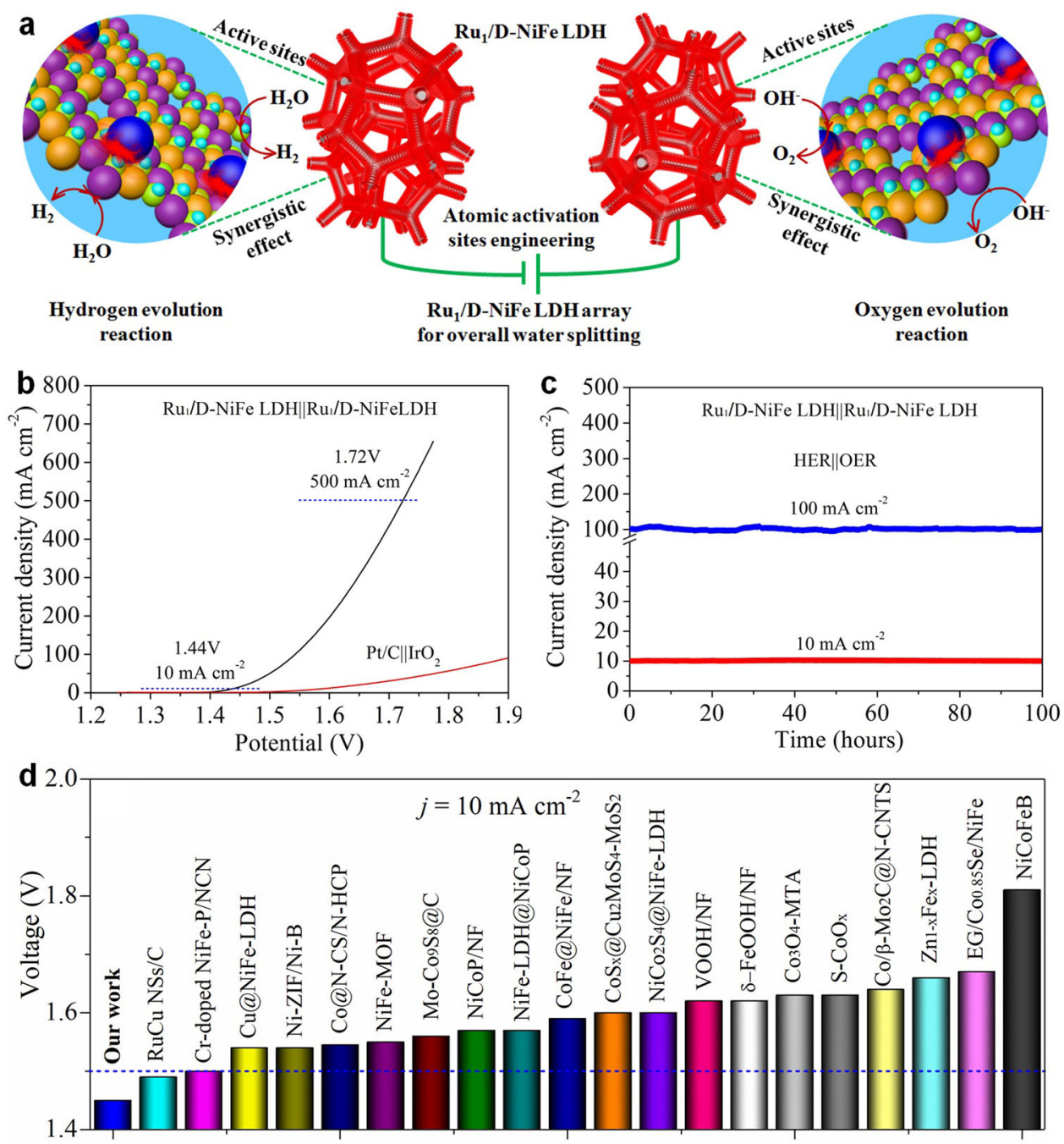

Overall water splitting in alkaline media

Fig. 5 Electrocatalytic performance for overall water splitting. a Schematic diagram of water splitting in a two-electrode configuration, (b) polarization curves by two-electrode system, $\mathbf{c}$ chronoamperometric test of $\mathrm{Ru}_{1} / \mathrm{D}-\mathrm{NiFe} \mathrm{LDH}$ with current densities of 10 and $100 \mathrm{~mA} \mathrm{~cm}{ }^{-2}$ at 1.44 and $1.54 \mathrm{~V}$, and d comparison of the cell voltages at $10 \mathrm{~mA} \mathrm{~cm}{ }^{-2}$ for $\mathrm{Ru}_{1} / \mathrm{D}-\mathrm{NiFe} \mathrm{LDH}$ with reported bifunctional electrocatalysts.

degradation of the current densities of 10 and $100 \mathrm{~mA} \mathrm{~cm}^{-2}$ at constant potentials of 1.44 and $1.54 \mathrm{~V}$ over $100 \mathrm{~h}$, indicating the good durability. After long-term electrocatalysis, there is a positive shift of two peaks at 856.5 and $874.3 \mathrm{eV}$ for the $\mathrm{Ni} 2 p$ XPS (Supplementary Fig. 27), confirming the formation of high valence state of $\mathrm{Ni}^{3+}$ from the oxidation of $\mathrm{Ni}^{2+23,57-61}$. In addition, a new peak located at $869.1 \mathrm{eV}$ occured in the XPS of Ni $2 p$, demonstrating the existence of oxyhydroxides as the active sites after long-term OER. However, there is little change in the morphologies and components of $\mathrm{Ru}_{1} / \mathrm{D}-\mathrm{NiFe} \mathrm{LDH}$ after HER and OER by use of SEM and element mappings (Supplementary Figs. 28-30). Additionally, the atomic dispersion of Ru single atoms in $\mathrm{D}$-NiFe $\mathrm{LDH}$ after long-tern OER is maintained (Supplementary Fig. 31). The combined analysis of these results demonstrates the potential of $\mathrm{Ru}$ single atoms stabilized on defective $\mathrm{NiFe}-\mathrm{LDH}$ as a promising candidate towards overall water splitting.

To gain in-depth insights into the structure evolution and electrocatalytic mechanism during OER process, in-situ Raman spectra was used from open circuit voltage (OCV) to $1.7 \mathrm{~V}$ vs. RHE in $1 \mathrm{M} \mathrm{KOH}$. When the applied potential was higher than $1.4 \mathrm{~V}$ vs. RHE, a pair of characteristic Raman peaks appeared at 447 and $557 \mathrm{~cm}^{-1}$, which can be assigned to the $\mathrm{Ni}^{3+}-\mathrm{O} e_{\mathrm{g}}$ bending and $A_{1 \mathrm{~g}}$ stretching vibrations of $\gamma-\mathrm{NiOOH}$ (Supplementary Fig. 32a), indicating the pristine structure transformed to the oxyhydroxides under oxygen evolution potential ${ }^{62-64}$. Interestingly, when the potential decreases from 1.7 to $1.2 \mathrm{~V}$ vs. RHE, the peak of $\gamma-\mathrm{NiOOH}$ disappeared, suggesting the oxyhydroxides transformed back to LDH (Supplementary Fig. 32b). In brief, these results reveal that the reversible transformation between $\mathrm{LDH}$ and the oxyhydroxides are the real active species.

First-principles calculations. DFT calculations were performed to identify the active sites in $\mathrm{Ru}_{1} / \mathrm{D}-\mathrm{NiFe} \mathrm{LDH}$. The Gibbs free energy for each elementary reaction step in HER and OER were explored. The hydrogen absorption energy $\left(\Delta G_{\mathrm{H}^{*}}\right)$ of adsorbed $\mathrm{H}$ is a key descriptor for evaluating the HER performance ${ }^{3,29,65}$. The adsorption structures of $\mathrm{H}$ at $\mathrm{Ni}$ and $\mathrm{Fe}$ sites in $\mathrm{NiFe} \mathrm{LDH}$, and $\mathrm{Ru}$ site on $\mathrm{Ru}_{1} / \mathrm{D}-\mathrm{NiFe} \mathrm{LDH}$ s were modeled (Supplementary Fig. 33a-c). Compared with $\Delta G_{\mathrm{H}^{*}}$ of adsorbed $\mathrm{H}$ at Ni site $(1.53$ $\mathrm{eV}$ ) and Fe site (1.16 eV) in NiFe LDH (Supplementary Fig. 33d), $\mathrm{H}$ adsorption at the $\mathrm{Ru}$ site on $\mathrm{Ru}_{1} / \mathrm{D}-\mathrm{NiFe} \mathrm{LDH}$ has a lower $\Delta G_{\mathrm{H}^{*}}$ value of $0.25 \mathrm{eV}$, indicating that the $\mathrm{Ru}$ site has more favorable enthalpy of hydrogen adsorption and simultaneous decrease in the thermodynamic barriers for hydrogen production. The DFT results demonstrate the importance of the synergistic 
a

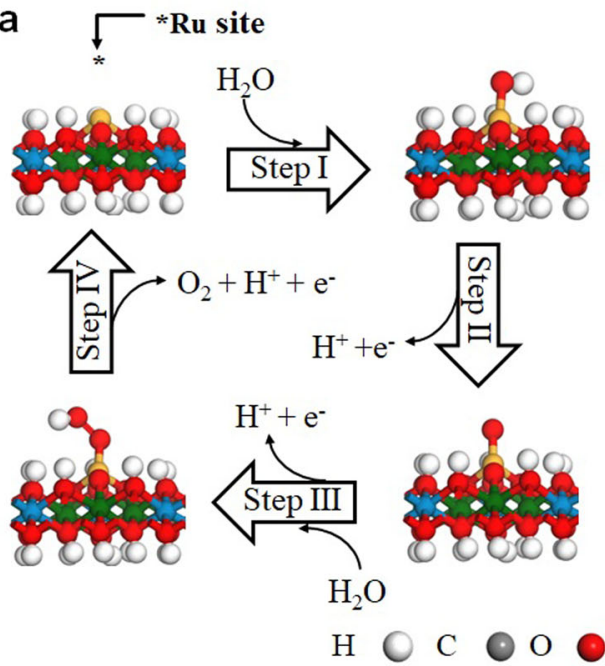

b

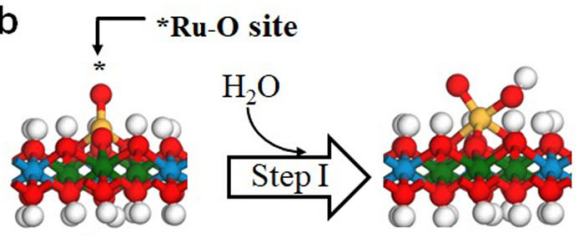

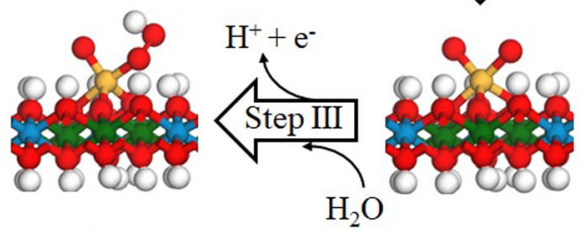

$\mathrm{Fe} \odot \mathrm{Ni} \odot \mathrm{Ru}$

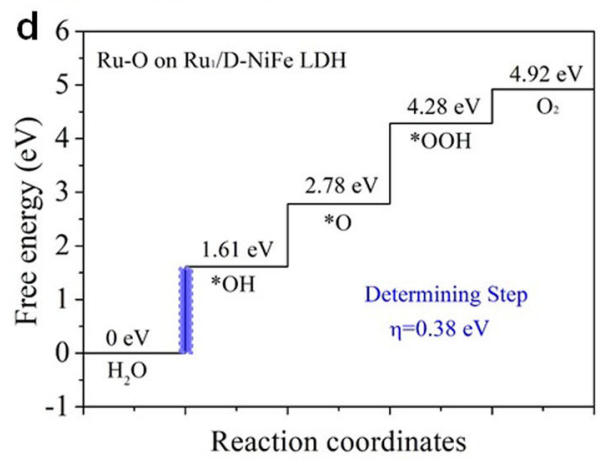

Fig. 6 DFT calculations. a, b Schematic illustration of the proposed OER mechanism and $\mathbf{c}$, $\mathbf{d}$ Gibbs free energy diagram for $\mathbf{a}$, $\mathbf{c}$ Ru and $\mathbf{b}$, $\mathbf{d}$ Ru-O sites on $\mathrm{Ru}_{1} / \mathrm{D}-\mathrm{NiFe} \mathrm{LDH}$. The lavender box step is the rate-determining step.

effect between the isolated $\mathrm{Ru}$ single atoms and defective LDH for high hydrogen evolution rates in alkaline medium.

DFT modeling of the water oxidation mechanism involving four concerted proton-electron transfer steps was also analyzed in alkaline medium. As shown in Fig. 6, each elementary reaction step of Gibbs free energy was calculated. The edge sites of $\mathrm{Ni}$ and $\mathrm{Fe}$ in $\mathrm{NiFe} \mathrm{LDH}$ were selected as the active site for OER. For NiFe $\mathrm{LDH}$, the transition from $\mathrm{O}^{*}$ to $\mathrm{OOH}^{*}$ and the formation $\mathrm{O}^{*}$ from $\mathrm{OH}^{*}$ are the rate-determining steps for Fe sites and $\mathrm{Ni}$ sites, respectively (Supplementary Figs. 34, 35) ${ }^{5}$. The large Gibbs free energies of the rate-determining step for $\mathrm{Fe}$ and $\mathrm{Ni}$ sites lead to low $\mathrm{O}_{2}$ rates, presenting the sluggish OER kinetics. The DFT results suggest that the rate-determining step for $\mathrm{Ru}$ site on $\mathrm{Ru}_{1} /$ $\mathrm{D}-\mathrm{NiFe} \mathrm{LDH}$ is the transition $\mathrm{O}^{*}$ to $\mathrm{OOH}^{*}$, with the overpotential of $1.71 \mathrm{eV}$ (Fig. 6a). Surprisingly, the Gibbs free energy of $\mathrm{Ru}$ sites is higher than those of $\mathrm{Fe}$ and $\mathrm{Ni}$ sites in $\mathrm{NiFe} \mathrm{LDH}$, which is not in agreement with the electrocatalytic performance of $\mathrm{Ru}_{1} / \mathrm{D}-\mathrm{NiFe} \mathrm{LDH}$. From previous reports, $\mathrm{M}-\mathrm{O}(\mathrm{M}=\mathrm{Ir}, \mathrm{Ru})$ was shown as the likely reaction site during $\mathrm{OER}^{5,30}$. Herein, $\mathrm{Ru}-\mathrm{O}$ moiety on $\mathrm{Ru}_{1} / \mathrm{D}-\mathrm{NiFe} \mathrm{LDH}$ (Fig. $6 \mathrm{~b}$ ) was proposed as the active site and modeled for the four elementary OER reaction steps. The rate-determining step for $\mathrm{Ru}-\mathrm{O}$ site on $\mathrm{Ru}_{1} / \mathrm{D}-\mathrm{NiFe}$ $\mathrm{LDH}$ is the formation of $\mathrm{OH}^{*}$. With this active site structure, the overpotential of the rate-determining step for $\mathrm{Ru}-\mathrm{O}$ site decreased to $0.38 \mathrm{eV}$, which is even lower that those of $\mathrm{Fe}-\mathrm{O}$ and $\mathrm{Ni}-\mathrm{O}$ sites, expediting the OER kinetics. Thus, both experiment and theoretical simulation confirm that the synergetic effect between $\mathrm{Ru}$ single atoms and defective $\mathrm{NiFe} \mathrm{LDH}$ is beneficial to accelerate the reaction kinetics and thus promote the enhancement of electrocatalytic performance of $\mathrm{Ru}_{1} / \mathrm{D}-\mathrm{NiFe}$ LDH.

\section{Discussion}

In summary, a simple and scalable electrocatalytic synthesis strategy is described for stabilization of large number of single atom ruthenium sites on defective NiFe LDH. Based on the precise regulation of local coordination environments of the active sites and the existence of the defects, $\mathrm{Ru}_{1} / \mathrm{D}-\mathrm{NiFe} \mathrm{LDH}$ achieves superior HER and OER performance in alkaline media with low overpotential, high current density and long-term durability. The well-defined structures of the catalysts also allow for fundamental investigation into the reaction steps and kinetics of the HER and OER reactions. For example, DFT calculations reveal that $\mathrm{Ru}_{1} / \mathrm{D}-\mathrm{NiFe} \mathrm{LDH}$ promotes the favorable regulation of $\mathrm{H}$ adsorption energies for $\mathrm{HER}$, and facilitates the $\mathrm{O}-\mathrm{O}$ coupling for OER. For the OER, the Ru-O moiety is proposed as active site for high rates of $\mathrm{O}_{2}$ formation. This work not only develops a simple and practical strategy for the synthesis of $\mathrm{Ru}_{1} / \mathrm{D}-\mathrm{NiFe}$ $\mathrm{LDH}$, but also theoretically/experimentally confirms the pivotal roles of single atoms in unexpectedly optimizing electrocatalytic activity, opening up new opportunities for efficient and stable electrocatalysts with potential for the development of an improved commercial water splitting process.

\section{Methods}

Synthesis of $\mathbf{R} \mathbf{u}_{\mathbf{1}} / \mathbf{D}-\mathbf{N i F e} \mathbf{L D H s}$. The electrolyte was containing $0.12 \mathrm{M} \mathrm{Ni}$ $\left(\mathrm{NO}_{3}\right)_{2} \cdot 6 \mathrm{H}_{2} \mathrm{O}, 0.12 \mathrm{M} \mathrm{Fe}\left(\mathrm{NO}_{3}\right)_{3} \cdot 9 \mathrm{H}_{2} \mathrm{O}, 0.001 \mathrm{M} \mathrm{Al}\left(\mathrm{NO}_{3}\right)_{3} \cdot 9 \mathrm{H}_{2} \mathrm{O}$ and $0.01-0.06 \mathrm{M}$ $\mathrm{RuCl}_{3} \cdot x \mathrm{H}_{2} \mathrm{O}$. A constant potential electrodeposition was conducted at $-1.0 \mathrm{~V}$ vs. $\mathrm{Ag} / \mathrm{AgCl}$ for a certain time. Ru single atoms stabilized NiFeAl LDH (denoted as $\mathrm{Ru}_{1} / \mathrm{NiFeAl} \mathrm{LDH}$ ) as the precursor was fabricated by electrodeposition approach Then, $\mathrm{Ru}_{1} / \mathrm{NiFeAl} \mathrm{LDH}$ supported on nickel foam was immersed in $5 \mathrm{M} \mathrm{NaOH}$ solution under continuous stirring for various times $(12,24$, and $36 \mathrm{~h})$. After alkaline etching treatment, Ru single atoms integrated defective $\mathrm{NiFe} \mathrm{LDH}$ (denoted as $\mathrm{Ru}_{1} / \mathrm{D}-\mathrm{NiFe} \mathrm{LDH}$ ) nanosheets were obtained. In comparison, $\mathrm{Ru}_{1} /$ 
NiFe LDH was synthesized by the same procedure of $\mathrm{Ru}_{1} / \mathrm{D}-\mathrm{NiFe} \mathrm{LDH}$ without alkaline etching, by use of $0.12 \mathrm{M} \mathrm{Ni}\left(\mathrm{NO}_{3}\right)_{2} \cdot 6 \mathrm{H}_{2} \mathrm{O}, 0.12 \mathrm{M} \mathrm{Fe}\left(\mathrm{NO}_{3}\right)_{3} \cdot 9 \mathrm{H}_{2} \mathrm{O}$, and $0.01-0.06 \mathrm{M} \mathrm{RuCl}_{3} \cdot \times \mathrm{H}_{2} \mathrm{O}$. NiFe LDH was fabricated by the same procedure of $\mathrm{Ru}_{1} /$ $\mathrm{D}-\mathrm{NiFe} \mathrm{LDH}$, without use of $\mathrm{RuCl}_{3} \cdot x \mathrm{H}_{2} \mathrm{O}$ and alkaline etching.

Structural characterization. Powder XRD patterns were characterized using X-ray diffractometer (Japan Rigaku Rotaflex) by $\mathrm{Cu} \mathrm{K}_{\alpha}$ radiation $(\lambda=1.5418 \AA$ ). SEM tests were recorded on Nova NanoSEM 450. TEM and HAADF-STEM images were performed on FEI TF30. Spherical aberration-corrected TEM images were characterized on a JEM ARM200F thermal-field emission microscope with a probe spherical aberration corrector. XPS data was tested by a model of ESCALAB250. Inductively coupled plasma-optical emission spectrometer (ICP-OES) was characterized on PerkinElmer AVIO 500. In-situ Raman experiments were conducted with a Raman spectrometer (Thermo Fisher, DXR Microscope) with a $\times 50$ visible objective. The wavenumber of the excitation light source was $532 \mathrm{~nm}$. Atomic force microscope (AFM, Bruck Dimension Icon) was utilized to analyze the thickness of the product. X-ray absorption fine structure spectra (XAFS) of $\mathrm{Ni}, \mathrm{Fe}$, and $\mathrm{Ru} \mathrm{K}$ edge were collected at BL07A1 beamline of National Synchrotron Radiation Research Center (NSRRC). The data were collected in fluorescence mode using a Lytle detector.

Electrochemical measurements. The electrochemical measurements were conducted by a standard three-electrode cell with the connection of an electrochemical workstation. As-synthesized LDH-based electrode was employed as the working electrode. A graphite rod was applied as the counter electrode. $\mathrm{Hg} / \mathrm{HgO}$ electrode was utilized as the reference electrode. The potentials were converted to RHE by the equation, $E_{\mathrm{RHE}}=E_{\mathrm{Hg} / \mathrm{HgO}}+0.059 \mathrm{pH}+0.098 \mathrm{~V}$. The geometric surface area of the catalysts supported $\mathrm{Ni}$ foam is $1 \mathrm{~cm}^{2}$, corresponding the mass loading of $\mathrm{Ru}_{1} /$ $\mathrm{D}-\mathrm{NiFe} \mathrm{LDHs}\left(2 \mathrm{mg} \mathrm{cm}^{-2}\right)$. In comparison, $20 \mathrm{wt} \% \mathrm{Pt} / \mathrm{C}$ and $\mathrm{IrO}_{2}$ inks were dropcast onto $\mathrm{Ni}$ foam, producing $\mathrm{Pt} / \mathrm{C}$ and $\mathrm{IrO}_{2}$ electrodes for electrochemical tests. The HER and OER polarization curves were measured by a LSV approach with a sweeping rate of $1 \mathrm{mV} \mathrm{s}^{-1}$ in nitrogen- and oxygen-saturated $1 \mathrm{M} \mathrm{KOH}$ media at $25^{\circ} \mathrm{C}$. EIS was performed within the frequency range from $100 \mathrm{kHz}$ to $0.1 \mathrm{~Hz}$ With regard to the measurement of $\mathrm{FE}$, the gaseous products were conducted by gas chromatography (Shimadzu, GC-2014). For determination of FE, the efficiency of HER or OER catalysts is defined as the ratio of the amount of experimentally determined hydrogen or oxygen to that of the theoretically expected hydrogen or oxygen from the HER or OER reaction in $1 \mathrm{M} \mathrm{KOH}$ solution. The calculation of mass activity, TOF measurement and XANES simulation were presented (Supplementary Notes $1-3)$.

First-principle calculations. All DFT calculations were performed by the Vienna $\mathrm{ab}$ initio simulation package (VASP) ${ }^{66}$. The projector augmented wave pseudopotentials and the generalized gradient approximation parameterized by Perdew-Burke-Ernzerhof (GGA-PBE) for exchange-correlation functional ${ }^{67}$. The core electrons were descripted by the Projector-augmented wave (PAW) technology. The Brillouin zones of the supercells were sampled by $1 \times 2 \times 3$ uniform $k$ point mesh ${ }^{66}$. With fixed cell parameters, the model structures were fully optimized using the convergence criteria of $10^{-5} \mathrm{eV}$ for the electronic energy and $10^{-2} \mathrm{eV} / \AA$ for the forces on each atom and the plane wave cutoff was set to $400 \mathrm{eV}$. The supercells dimension in $y$ and $z$ was 10.14 and $6.44 \AA$, respectively. The vacuum region in the $z$ direction was adopted large than $20 \AA$. Both spin-polarized and spin-unpolarized computations were performed. Considering the strong $d$-electron correlation effects for Fe and $\mathrm{Ni}, \mathrm{DFT}+U$ method was used in this work with $U=$ $3.9 \mathrm{eV}$ and $J=0 \mathrm{eV}$ for Fe and $U=2.9 \mathrm{eV}$ and $J=0 \mathrm{eV}$ for Ni. and $U=3.4 \mathrm{eV}$ and $J=0 \mathrm{eV}$ for Ru.

The Gibbs free energy of the intermediates for HER and OER process, that is, ${ }^{*} \mathrm{H},{ }^{*} \mathrm{OH},{ }^{*} \mathrm{O}$, and ${ }^{*} \mathrm{OOH}$, can be calculated as

$$
\Delta G=E_{\text {ads }}+\Delta E_{\mathrm{ZPE}}-T \Delta S-\Delta G(p H)+e U
$$

Here $E_{\text {ads }}$ is the adsorption energy of intermediate, $\Delta E_{\mathrm{ZPE}}$ is the zero point energy difference between the adsorption state and gas state, $T$ is the temperature $(300 \mathrm{~K}), \Delta S$ is the entropy various between the adsorption and gas phase.

The intermediates adsorption energy $E_{\text {ads }}$ for ${ }^{*} \mathrm{H},{ }^{*} \mathrm{OH},{ }^{*} \mathrm{O}$ and ${ }^{*} \mathrm{OOH}$ can be used DFT ground state energy calculated $\mathrm{as}^{68}$

$$
\begin{gathered}
\Delta E_{*_{M H}}=E\left({ }^{*} M H\right)-E\left({ }^{*}\right)-1 / 2 E\left(H_{2}\right) \\
\Delta E_{*_{\mathrm{OOH}}}=E\left({ }^{*} \mathrm{OOH}\right)-E\left(^{*}\right)-\left(2 E_{\mathrm{H}_{2} \mathrm{O}}-3 / 2 E_{\mathrm{H}_{2}}\right) \\
\Delta E_{*_{\mathrm{O}}}=E\left({ }^{*} \mathrm{O}\right)-E\left({ }^{*}\right)-\left(E_{\mathrm{H}_{2} \mathrm{O}}-E_{\mathrm{H}_{2}}\right) \\
\Delta E_{*_{\mathrm{OH}}}=E\left({ }^{*} \mathrm{OH}\right)-E\left({ }^{*}\right)-\left(E_{\mathrm{H}_{2} \mathrm{O}}-1 / 2 E_{\mathrm{H}_{2}}\right)
\end{gathered}
$$

The OER process usually summarized in four steps

$$
\begin{array}{lr}
*+\mathrm{H}_{2} \mathrm{O} \rightarrow{ }^{*} \mathrm{OH}+\mathrm{H}^{+}+e^{-} . & \Delta G_{I} \\
* \mathrm{OH} \rightarrow{ }^{*} \mathrm{O}+\mathrm{H}^{+}+e^{-} . & \Delta G_{I I} \\
*+\mathrm{H}_{2} \mathrm{O} \rightarrow{ }^{*} \mathrm{OOH}+H^{+}+e^{-} . & \Delta G_{I I I} \\
* \mathrm{OOH} \rightarrow \mathrm{O}_{2}+H^{+}+e^{-}+* & \Delta G_{I V}
\end{array}
$$

Here $*$ denotes adsorption active site on the substrate.

$$
\begin{gathered}
\Delta G_{I}=\Delta G_{*_{\mathrm{OH}}} \\
\Delta G_{I I}=\Delta G_{*_{O}}-\Delta G_{*_{\mathrm{OH}}} \\
\Delta G_{I I I}=\Delta G_{*_{\mathrm{OOH}}}-\Delta G_{*_{O}} \\
\Delta G_{I V}=4.92-\Delta G_{* \mathrm{OOH}}
\end{gathered}
$$

The overpotential $(\eta)$ is defined as below:

$$
\eta=\max \left\{\Delta G_{I}, \Delta G_{I I}, \Delta G_{I I I}, \Delta G_{I V}\right\}-1.23 \mathrm{eV}
$$

\section{Data availability}

The data that support the findings of this work are available from the corresponding author upon reasonable request.

Received: 30 November 2020; Accepted: 7 July 2021; Published online: 28 July 2021

\section{References}

1. Chu, S. \& Majumdar, A. Opportunities and challenges for a sustainable energy future. Nature 488, 294-303 (2012).

2. Zhang, B. et al. Homogeneously dispersed multimetal oxygen-evolving scatalysts. Science 352, 333-337 (2016).

3. Jiang, K. et al. Single platinum atoms embedded in nanoporous cobalt selenide as electrocatalyst for accelerating hydrogen evolution reaction. Nat. Commun. 10, 1743 (2019).

4. Yu, F. Y. et al. Pt-O bond as an active site superior to $\mathrm{Pt}(0)$ in hydrogen evolution reaction. Nat. Commun. 11, 490 (2020).

5. Jiang, K. et al. Dynamic active-site generation of atomic iridium stabilized on nanoporous metal phosphides for water oxidation. Nat. Commun. 11, 2701 (2020).

6. Kweon, D. H. et al. Ruthenium anchored on carbon nanotube electrocatalyst for hydrogen production with enhanced Faradaic efficiency. Nat. Commun. 11, $1278(2020)$

7. Liu, Y. et al. Corrosion engineering towards efficient oxygen evolution electrodes with stable catalytic activity for over 6000 h. Nat. Commun. 9, 2609 (2018).

8. Yan, Z. et al. Anion insertion enhanced electrodeposition of robust metal hydroxide/oxide electrodes for oxygen evolution. Nat. Commun. 9, 2373 (2018).

9. Lu, X. \& Zhao, C. Electrodeposition of hierarchically structured threedimensional nickel-iron electrodes for efficient oxygen evolution at high current densities. Nat. Commun. 6, 6616 (2015).

10. Lee, S., Bai, L. \& Hu, X. Deciphering iron-dependent activity in oxygen evolution catalyzed by nickel-iron layered double hydroxide. Angew. Chem. Int. Ed. 59, 8072-8077 (2020).

11. Dionigi, F. et al. In-situ structure and catalytic mechanism of NiFe and $\mathrm{CoFe}$ layered double hydroxides during oxygen evolution. Nat. Commun. 11, 2522 (2020).

12. Jiang, J. et al. Atomic-level insight into super-efficient electrocatalytic oxygen evolution on iron and vanadium co-doped nickel (oxy)hydroxide. Nat. Commun. 9, 2885 (2018).

13. Yan, J. et al. Single atom tungsten doped ultrathin $\alpha-\mathrm{Ni}(\mathrm{OH})_{2}$ for enhanced electrocatalytic water oxidation. Nat. Commun. 10, 2149 (2019).

14. Wang, J., Tan, C. F., Zhu, T. \& Ho, G. W. Topotactic consolidation of monocrystalline CoZn hydroxides for advanced oxygen evolution electrodes. Angew. Chem. Int. Ed. 55, 10326-10330 (2016).

15. Song, F. \& Hu, X. Ultrathin cobalt-manganese layered double hydroxide is an efficient oxygen evolution catalyst. J. Am. Chem. Soc. 136, 16481-16484 (2014). 
16. Huang, Z. F. et al. Chemical and structural origin of lattice oxygen oxidation in Co-Zn oxyhydroxide oxygen evolution electrocatalysts. Nat. Energy 4, 329-338 (2019).

17. $\mathrm{Wu}, \mathrm{X}$. et al. Hierarchically structured $\mathrm{FeNiO}_{x} \mathrm{H}_{y}$ electrocatalyst formed by in situ transformation of metal phosphate for efficient oxygen evolution reaction. ChemSusChem. 11, 1761-1767 (2018).

18. Fan, K. et al. Nickel-vanadium monolayer double hydroxide for efficient electrochemical water oxidation. Nat. Commun. 7, 11981 (2016).

19. $\mathrm{Du}$, J. et al. Iron-salen complex and $\mathrm{Co}^{2+}$ ion-derived cobalt-iron hydroxide/ carbon nanohybrid as an efficient oxygen evolution electrocatalyst. Adv. Sci. 6, 1900117 (2019).

20. Hou, J. et al. Rational design of nanoarray architectures for electrocatalytic water splitting. Adv. Funct. Mater. 29, 1808367 (2019).

21. Tang, Y. et al. Activating the hydrogen evolution and overall water splitting performance of NiFe LDH by cation doping and plasma reduction. Appl. Catal. B 266, 118627 (2020).

22. Yan, D. et al. Defect chemistry of nonprecious-metal electrocatalysts for oxygen reactions. Adv. Mater. 29, 1606459 (2017).

23. Gao, Z. W. et al. Engineering $\mathrm{NiO} / \mathrm{NiFe} \mathrm{LDH}$ intersection to bypass scaling relationship for oxygen evolution reaction via dynamic tridimensional adsorption of intermediates. Adv. Mater. 31, 1804769 (2019).

24. Xiao, Z. et al. Filling the oxygen vacancies in $\mathrm{Co}_{3} \mathrm{O}_{4}$ with phosphorus: an ultra-efficient electrocatalyst for overall water splitting. Energy Environ. Sci. 10, 2563-2569 (2017).

25. Yin, Y. et al. Contributions of phase, sulfur vacancies, and edges to the hydrogen evolution reaction catalytic activity of porous molybdenum disulfide nanosheets. J. Am. Chem. Soc. 138, 7965-7972 (2016).

26. Liu, B. et al. Iron vacancies induced bifunctionality in ultrathin feroxyhyte nanosheets for overall water splitting. Adv. Mater. 30, 1803144 (2018).

27. Chen, D. et al. Preferential cation vacancies in perovskite hydroxide for the oxygen evolution reaction. Angew. Chem. Int. Ed. 57, 8691-8696 (2018).

28. Wang, Y. et al. Layered double hydroxide nanosheets with multiple vacancies obtained by dry exfoliation as highly efficient oxygen evolution electrocatalysts. Angew. Chem. Int. Ed. 56, 5867-5871 (2017).

29. Li, P. et al. Boosting oxygen evolution of single-atomic ruthenium through electronic coupling with cobalt-iron layered double hydroxides. Nat. Commun. 10, 1711 (2019).

30. Zhang, J. et al. Single-atom Au/NiFe layered double hydroxide electrocatalyst: probing the origin of activity for oxygen evolution reaction. J. Am. Chem. Soc. 140, 3876-3879 (2018).

31. Lim, T. et al. Atomically dispersed $\mathrm{Pt}-\mathrm{N}_{4}$ sites as efficient and selective electrocatalysts for the chlorine evolution reaction. Nat. Commun. 11, 412 (2020).

32. Liu, D. et al. Atomically dispersed platinum supported on curved carbon supports for efficient electrocatalytic hydrogen evolution. Nat. Energy 4 , 512-518 (2019).

33. Qiao, B. et al. Single-atom catalysis of $\mathrm{CO}$ oxidation using $\mathrm{Pt}_{1} / \mathrm{FeO}_{x}$. Nat. Chem. 3, 634-641 (2011).

34. Qu, Y. et al. Direct transformation of bulk copper into copper single sites via emitting and trapping of atoms. Nat. Catal. 1, 781-786 (2018).

35. Liu, D. et al. Atomically dispersed platinum supported on curved carbon supports for efficient electrocatalytic hydrogen evolution. Nat. Energy 4, 512-518 (2019).

36. Bliem, R. et al. Subsurface cation vacancy stabilization of the magnetite (001). Surf. Sci. 346, 1215-1218 (2014).

37. Zhang, J. et al. Cation vacancy stabilization of single-atomic-site $\mathrm{Pt}_{1} / \mathrm{Ni}(\mathrm{OH})_{x}$ catalyst for diboration of alkynes and alkenes. Nat. Commun. 9, 1002 (2018).

38. Wan, J. et al. Defect effects on $\mathrm{TiO}_{2}$ nanosheets: stabilizing single atomic site $\mathrm{Au}$ and promoting catalytic properties. Adv. Mater. 30, 1705369 (2018).

39. Asnavandi, M. et al. Promoting oxygen evolution reactions through introduction of oxygen vacancies to benchmark $\mathrm{NiFe}-\mathrm{OOH}$ catalysts. ACS Energy Lett. 7, 1515-1520 (2018).

40. Song, L. et al. Achieving efficient alkaline hydrogen evolution reaction over a $\mathrm{Ni}_{5} \mathrm{P}_{4}$ catalyst incorporating single-atomic Ru sites. Adv. Mater. 32, 1906972 (2020).

41. Genovese, C. et al. Operando spectroscopy study of the carbon dioxide electro-reduction by iron species on nitrogen-doped carbon. Nat. Comm. 9, 935 (2018).

42. Wang, Y., Qiao, M., Li, Y. \& Wang, S. Tuning surface electronic configuration of NiFe LDHs nanosheets by introducing cation vacancies (Fe or Ni) as highly efficient electrocatalysts for oxygen evolution reaction. Small 14, 1800136 (2018).

43. Han, X. et al. Ultrasensitive iron-triggered nanosized $\mathrm{Fe}-\mathrm{CoOOH}$ integrated with graphene for highly efficient oxygen evolution. Adv. Energy Mater. 7, 1602148 (2017).
44. Wang, D. et al. Atomic and electronic modulation of self-supported nickelvanadium layered double hydroxide to accelerate water splitting kinetics. Nat. Commun. 10, 3899 (2019).

45. Chen, G. et al. Accelerated hydrogen evolution kinetics on NiFe-layered double hydroxide electrocatalysts by tailoring water dissociation active sites. Adv. Mater. 30, 1706279 (2018).

46. Ping, J. et al. Self-assembly of single-layer CoAl-layered double hydroxide nanosheets on $3 \mathrm{D}$ graphene network used as highly efficient electrocatalyst for oxygen evolution reaction. Adv. Mater. 28, 7640-7645 (2016).

47. Qin, M. et al. Unprecedented synthesis of holey $2 \mathrm{D}$ layered double hydroxide nanomesh for enhanced oxygen evolution. Adv. Energy Mater. 9, 1803060 (2019).

48. He, K. et al. Utilizing the space-charge region of the FeNi-LDH/CoP p-n junction to promote performance in oxygen evolution electrocatalysis. Angew. Chem. Int. Ed. 58, 11903-11909 (2019).

49. Liu, R., Wang, Y., Liu, D., Zou, Y. \& Wang, S. Water-plasma-enabled exfoliation of ultrathin layered double hydroxide nanosheets with multivacancies for water oxidation. Adv. Mater. 29, 1701546 (2017).

50. Jia, Y. et al. A heterostructure coupling of exfoliated Ni-Fe hydroxide nanosheet and defective graphene as a bifunctional electrocatalyst for overall water splitting. Adv. Mater. 29, 1700017 (2017).

51. Yin, S. et al. A highly efficient oxygen evolution catalyst consisting of interconnected nickel-iron-layered double hydroxide and carbon nanodomains. Adv. Mater. 30, 1705106 (2018).

52. Zhang, X. et al. A simple synthetic strategy toward defect-rich rorous monolayer NiFe-layered double hydroxide nanosheets for efficient electrocatalytic water oxidation. Adv. Energy Mater. 9, 1900881 (2019).

53. Long, X. et al. A strongly coupled graphene and FeNi double hydroxide hybrid as an excellent electrocatalyst for the oxygen evolution reaction. Angew. Chem. Int. Ed. 53, 7584-7588 (2014).

54. Gong, M. et al. An advanced Ni-Fe layered double hydroxide electrocatalyst for water oxidation. J. Am. Chem. Soc. 135, 8452-8455 (2013).

55. Yu, L. et al. Non-noble metal-nitride based electrocatalysts for highperformance alkaline seawater electrolysis. Nat. Commun. 10, 5106 (2019).

56. Zhang, B. et al. Integrating $\mathrm{Rh}$ species with NiFe-layered double hydroxide for overall water splitting. Nano Lett. 20, 136-144 (2020).

57. Cai, Z. et al. Introducing $\mathrm{Fe}^{2+}$ into nickel-iron layered double hydroxide: local structure modulated water oxidation activity. Angew. Chem. Int. Ed. 57, 9392-9396 (2018).

58. Dionigi, F. \& Strasser, P. NiFe-based (oxy)hydroxide catalysts for oxygen evolution reaction in non-acidic electrolytes. Adv. Energy Mater. 6, 1600621 (2016).

59. Li, P. et al. Tuning electronic structure of NiFe layered double hydroxides with vanadium doping toward high efficient electrocatalytic water oxidation. Adv. Energy Mater. 8, 1703341 (2018).

60. Chung, D. Y. et al. Dynamic stability of active sites in hydr(oxy) oxides for the oxygen evolution reaction. Nat. Energy 5, 222-230 (2020).

61. Zhang, N. et al. Lattice oxygen activation enabled by high-valence metal sites for enhanced water oxidation. Nat. Commun. 11, 4066 (2020).

62. Yeo, B. S. \& Bell, A. T. In situ Raman study of nickel oxide and gold-supported nickel oxide catalysts for the electrochemical evolution of oxygen. J. Phys. Chem. C 116, 8394-8400 (2012).

63. Trzesniewski, B. J. et al. In situ observation of active oxygen species in $\mathrm{Fe}-$ containing Ni-based oxygen evolution catalysts: the effect of $\mathrm{pH}$ on electrochemical activity. J. Am. Chem. Soc. 137, 15112-15121 (2015).

64. Huang, J. et al. Identification of key reversible intermediates in selfreconstructed nickel-based hybrid electrocatalysts for oxygen evolution. Angew. Chem. Int. Ed. 58, 17458-17464 (2019).

65. Nørskov, J. K. et al. Trends in the exchange current for hydrogen evolution. J. Electrochem. Soc. 152, 23-26 (2005).

66. Kress, G. et al. Efficient iterative schemes for ab initio total-energy calculations using a plane-wave basis set. Phys. Rev. B 54, 11169 (1996).

67. Perdew, J. P., Burke, K. \& Ernzerhof, M. Generalized gradient approximation made simple. Phys. Rev. Lett. 77, 3865 (1996).

68. Mathew, K., Sundararaman, R., Letchworth-Weaver, K., Arias, T. A. \& Hennig, R. G. Implicit solvation model for density-functional study of nanocrystal surfaces and reaction pathways. J. Chem. Phys. 140, 084106 (2014).

\section{Acknowledgements}

This work was supported by National Natural Science Foundation of China (Nos. 21972015, 51672034, 12074053), Young top talents project of Liaoning Province (No. XLYC1907147, XLYC1907163), Joint Research Fund Liaoning-Shenyang National Laboratory for Materials Science (No. 2019JH3/30100003), the Fundamental Research Funds for the Central Universities (No. DUT20TD06) and the Liaoning Revitalization Talent Program (XLYC2008032). 


\section{Author contributions}

J.H. supervised the research. J.H., P.Z. and Y.W. conceived the research. P.Z. and Y.W. carried out the experiments, collected and analyzed the experimental data. P.Z. and S.C. performed SEM and TEM characterizations. M.X. and J.G. conducted theoretical calculations. P.Z., G.Z. and J.T.M. carried out XAS measurements and analysis. B.Z., Y.Z., Z. L., Z.F., C.W., X.Z. and L.S. offered help to analyze and discuss the experiment data. J.T. M. and L.S. gave helpful advice on the manuscript preparation. P.Z. and J.H. wrote the paper.

\section{Competing interests}

The authors declare no competing interests.

\section{Additional information}

Supplementary information The online version contains supplementary material available at https://doi.org/10.1038/s41467-021-24828-9.

Correspondence and requests for materials should be addressed to J.H.

Peer review information Nature Communications thanks Rosalie Hocking, Marcus Lundberg, Xiaoming Sun and other, anonymous, reviewers for their contributions to the peer review of this work. Peer review reports are available.
Reprints and permission information is available at http://www.nature.com/reprints

Publisher's note Springer Nature remains neutral with regard to jurisdictional claims in published maps and institutional affiliations.

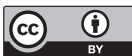

Open Access This article is licensed under a Creative Commons Attribution 4.0 International License, which permits use, sharing, adaptation, distribution and reproduction in any medium or format, as long as you give appropriate credit to the original author(s) and the source, provide a link to the Creative Commons license, and indicate if changes were made. The images or other third party material in this article are included in the article's Creative Commons license, unless indicated otherwise in a credit line to the material. If material is not included in the article's Creative Commons license and your intended use is not permitted by statutory regulation or exceeds the permitted use, you will need to obtain permission directly from the copyright holder. To view a copy of this license, visit http://creativecommons.org/ licenses/by/4.0/.

(C) The Author(s) 2021 